\title{
Model for computation of solar fraction in a single-slope solar still
}

\author{
A. Madhlopa ${ }^{1,2}$ and C. Johnstone \\ Energy Systems Research Unit, Department of Mechanical Engineering, University of Strathclyde, \\ 75 Montrose Street, Glasgow G1 1XJ, United Kingdom.
}

\begin{abstract}
A new model that calculates the distribution of solar radiation inside a single-slope solar still has been proposed. In this model, the solar fraction on a vertical surface is divided into beam and diffuse parts and the optical view factors of surfaces inside the still are taken into account. To validate the model, outdoor tests of a conventional solar still were conducted under different weather conditions at the University of Strathclyde. The proposed model is compared with the previous one. It is found that the beam solar fraction is affected by both the geometry of the solar still and position of the sun in the sky. In contrast, the diffuse solar fraction is only dependent on the geometry of the solar distiller. The present model exhibited a lower root mean square error than that of the previous model. It appears that splitting the solar fraction into beam and diffuse parts improves the accuracy of modelling the performance of a single-slope solar still.
\end{abstract}

Keywords: back wall, beam solar fraction, diffuse solar fraction, effective irradiance, view factor.

\section{Introduction}

Clean water is essential for the socio-economic development of any nation. Nevertheless, a large proportion of the available water on the earth's surface is salty (Tiwari et al., 2003), and environmental pollution caused predominantly by anthropogenic activities is also contributing $\underline{\text { to degradation of fresh water resources. So, there is limited access to safe drinking water }}$ especially in developing countries (WHO, 2008). Desalination is one method of producing fresh water from salty water.

Conventional techniques for desalination can broadly be classified into thermal and membrane based categories (Fritzmann et al., 2007). The former class of techniques includes $\underline{\text { multi-stage flash (MSF), multi-effect distillation (MED) and vapour compression distillation }}$ (VCD) while the latter class comprises reverse osmosis (RO), nanofiltration (NF) and

\footnotetext{
${ }^{1}$ Corresponding author: E-mail: amadhlopa@poly.ac.mw

${ }^{2}$ Permanent address: Malawi Polytechnic, P/Bag 303, Blantyre 3, Malawi.
} 
electrodialysis (ED). In thermal desalination, salts are removed from water by evaporationcondensation processes. Membrane based techniques employ a membrane through which water diffuses with a high proportion of the salts being retained. However, these techniques require a large input of energy and are not cost-effective for low demands of clean water (Mowla and Karimi, 1995). According to Bouchekima et al. (1998), improvements in solar distillation technology makes it ideal for desalting water in remote areas with water demands that are below $50 \mathrm{~m}^{3}$ per day. Delyannis (2003) presented a historical background of desalination and renewable energy, which includes advances in solar desalination. Tiwari et al. (2003) reviewed the status of solar distillation, and described solar distillation as the most famous non-conventional method for upgrading the quality of water.

The most widely-exploited solar distiller is a conventional solar still (Al-Kharabsheh and Goswami, 2003), which has a thin layer of saline water in a shallow basin, single-slope (or double-slope) transparent cover over the water and channel for collecting the distillate Saline water in the basin is heated by solar radiation passing through an inclined transparent cover and absorbed by the water and bottom part of the still basin. Vapour rises from the hot water and condenses when it comes into contact with the inner surface of the transparent cover. The condensate (clean water) is collected in a channel fitted along the lower edge of the transparent cover. For a given set of design parameters, the productivity of the system is influenced by climatic and operational factors, a single-slope solar still intercepts a higher proportion of solar radiation than a double-sloped solar still at both low and high latitude locations (Garg and Mann, 1976). In particular, solar radiation is the most influential 1976). Deleted: environmental parameter (Nafey et al., 2000). It is therefore necessary to know the amount of solar energy that drives thermal processes in the distiller.

_ Some attempts have been made to determine the proportion of incident solar radiation that contributes to the heat and mass transfer processes in a solar still. Cooper (1973) studied the 
factors that affect the efficiency of a single-slope solar still with a horizontal basin, taking into consideration the proportion of solar radiation reflected from the walls onto the surface of saline water. It was estimated that irradiance on the water increased by $10 \%$. Nevertheless, a model was not established for calculating the reported fraction. Tripathi and Tiwari (2004) proposed a model for computing the distribution of solar radiation inside a single-slope solar still. In their model, they also take into account the proportion of solar radiation reflected by the walls onto the water surface, and calculate the solar fraction for a particular wall. They found that the effect of solar fraction is significant at low solar altitudes. Later, Tripathi and Tiwari (2006) used the same model to study passive and active solar stills with a single slope. Again, they found that solar fraction was significantly influential at low solar altitudes. More recently, Tiwari and Tiwari (2007) studied the annual and seasonal performance of a conventional solar distiller with one slope by using the idea of solar fraction. Their results were in close conformity with findings from the other studies. _ The previous model proposed by Tripathi and Tiwari (2004) and used in subsequent studies, is realistic because it attempts to quantify the actual amount of solar energy that contributes to the heat and mass transfer processes in a solar still. In their analysis, the solar fraction on the back wall is computed from the azimuth and altitude angles of the sun, and the latitude and longitude of the site for a given geometry of the still. This indicates that the solar fraction provided by their model is derived based on the properties of beam radiation only. However, they applied the computed values of solar fraction to global irradiance, to obtain effective irradiance, which comprises both beam and diffuse components. Moreover, it is known that the two components of solar radiation have different optical properties when incident on a surface (Reindl et al., 1990; Duffie and Beckman ${ }_{2}$ 1991). Beam radiation travels directly from the sun's disc to a receiver surface, and its rays are traceable from the sun's position and used in determining the solar altitude and azimuth angles. These angles influence the amount of 
beam radiation directly reaching a given surface. In contrast, diffuse radiation comes from the whole sky vault and its rays are not traceable from the sun's position. In addition, the amount of diffuse solar energy directly received by a given surface depends on the proportion of the sky viewed by the surface (Duffie and Beckman 1991). Further, solar radiation reflected from a reflector to a receiver is influenced by both the reflectance and view factor of the reflector relative to the receiver (Duffie and Beckman,1991). In previous investigations on solar fraction, the optical view factors of surfaces inside the still are not taken into consideration. Consequently, models based on these findings will have limited accuracy, especially during periods of relatively high levels of diffuse radiation. The objective of this study was therefore to overcome this limitation. _. A new model has been developed by specifically taking into consideration the properties of beam and diffuse components of solar radiation and optical view factors inside a single-slope solar still. This model was applied to a solar still tested outdoors, at a higher latitude site at the University of Strathclyde from $6^{\text {th }}$ September to $5^{\text {th }}$ November 2007 . Results show that the beam and diffuse solar fractions have significantly different characteristics and it is found that the new model performs better than previous models on the concept of solar fraction.

\section{Proposed model}

\subsection{Solar fraction}

Solar radiation incident on the transparent cover (glass) on the top part of the still is reflected, absorbed and transmitted. The transmitted radiation reaches the surface of water and walls of a single slope solar still (Fig.1). A proportion of the radiation received by the walls is reflected onto the surface of the saline water. The water also reflects some of the total solar radiation received In this study, the beam and diffuse components of solar radiation are treated separately in determining the solar fraction on the wall. For beam radiation, solar energy received directly 
by the water surface $\left(\mathrm{G}_{\mathrm{bs}}\right)$ and that intercepted by the back wall $\left(\mathrm{G}_{\mathrm{bw}}\right)$ depend on the geometry of the solar still, beam irradiance on a horizontal surface and the position of the sun in the sky. So, $\mathrm{G}_{\mathrm{bs}}$ and $\mathrm{G}_{\mathrm{bw}}$ can be given by (Tripathi and Tiwari,2004):

$\mathrm{G}_{\mathrm{bs}}=\mathrm{A}_{\mathrm{sb}} \mathrm{G}_{\mathrm{bh}}$

$\mathrm{G}_{\mathrm{bw}}=\underline{\hat{A}}_{\mathrm{bw}} \mathrm{G}_{\mathrm{bh}}$

Using a geometric analysis as in Fig.2, the area of saline water receiving beam radiation directly $\left(\mathrm{A}_{\mathrm{sb}}\right)$ and the projected area of the back wall ( $\left.\mathrm{A}_{\mathrm{bw}}\right)$ are computed from the solar altitude and azimuth angles, and the latitude and longitude of the site:

$$
\begin{aligned}
& A_{s b}=L_{b l}\left(B_{b l}-\frac{Z_{f w} \cos \left(\gamma_{s}-\gamma\right)}{\tan \psi}\right) \\
& \hat{A}_{\mathrm{bw}}=\frac{L_{b l} Z_{b w} \cos \left(\gamma_{s}-\gamma\right)}{\tan \psi}
\end{aligned}
$$

The beam solar fraction on the wall $\left(\mathrm{F}_{\underline{b}}\right)$ is the ratio of $\mathrm{G}_{\underline{b w}} \underline{\text { to }}\left(\mathrm{G}_{\underline{b s}}+\mathrm{G}_{\underline{b w}}\right)$. Consequently, $F_{b}$ can be computed from:

$\mathrm{F}_{\mathrm{b}}=\frac{\hat{\mathrm{A}}_{\mathrm{bw}}}{A_{s b}+\hat{A}_{\mathrm{bw}}}$

At any specific time of the day, the solar altitude and azimuth angles are calculated according

to Duffie and Beckman (1991). It should be noted that both $\mathrm{A}_{\mathrm{sb}}$ and $\hat{A}_{\mathrm{bw}}$ vary with $\gamma_{\mathrm{s}}$ and $\psi$, for a given geometry of the solar still. This indicates that the two angles would also affect $F_{b}$. _For diffuse radiation, solar energy received directly by the water surface $\left(\mathrm{G}_{\mathrm{ds}}\right)$ and that intercepted by the back wall $\left(\mathrm{G}_{\mathrm{dw}}\right)$ depend on the view factors of surfaces within the solar still with respected to the sky and diffuse irradiance on a horizontal surface. Thus, $G_{d s}$ and $G_{d w}$ can be calculated from:

$\mathrm{G}_{\mathrm{ds}}=\mathrm{A}_{\mathrm{wl}} \mathrm{W}_{\mathrm{wl}-\mathrm{sk}} \mathrm{G}_{\mathrm{dh}}$

$\mathrm{G}_{\mathrm{dw}}=\mathrm{A}_{\mathrm{bw}} \mathrm{W}_{\mathrm{bw}-\mathrm{sk}} \mathrm{G}_{\mathrm{dh}}$
Deleted:

Deleted: $\mathrm{A}_{\mathrm{pw}}$

Deleted: The beam solar fraction on the wall $\left(\mathrm{F}_{\mathrm{b}}\right)$ is the ratio of $\mathrm{G}_{\mathrm{bw}}$ to $\left(\mathrm{G}_{\mathrm{bs}}+\mathrm{G}_{\mathrm{bw}}\right)$.

Deleted: $\left(\mathrm{A}_{\mathrm{pw}}\right)$

Deleted:

Deleted:

Deleted: $\mathrm{F}_{b}=\frac{A_{b w}^{\prime}}{A_{s b}+A_{b w}^{\prime}}$

Formatted: English (U.S.),

Lowered by $15 \mathrm{pt}$

Deleted:

Deleted: $\mathrm{A}_{\mathrm{pw}}$

Formatted: Not Superscript/

Subscript

Deleted:

Deleted: II 
Again, the diffuse solar fraction on the wall $\left(F_{d}\right)$ is the ratio of $G_{d w}$ to $\left(G_{d s}+G_{d w}\right)$. So, $F_{d}$ can be given by:

$\mathrm{F}_{\mathrm{d}}=\frac{\mathrm{A}_{\mathrm{bw}} \mathrm{W}_{\mathrm{bw}-\mathrm{sk}}}{\mathrm{A}_{\mathrm{wl}} \mathrm{W}_{\mathrm{wl-sk}}+\mathrm{A}_{\mathrm{bw}} \mathrm{W}_{\mathrm{bw}-\mathrm{sk}}}$

It is observed that $F_{d}$ is a function of only the geometric parameters of the solar still, which indicates that the diffuse solar fraction is not affected by the position of the sun.

\subsection{Effective beam and diffuse solar irradiance}

_ Saline water receives solar energy directly from the sun and indirectly from the walls of the still. The amount of solar energy reflected by a particular wall is also influenced by the view factor of the wall with respect to the water surface. For beam radiation, solar energy received by the water can be given by:

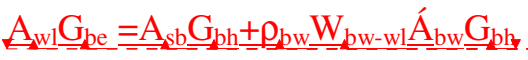

Using Eqs.(3-5) and (9), the effective beam irradiance inside the solar still is calculated from:

$\mathrm{G}_{\mathrm{be}}=\left(\frac{\mathrm{A}_{\mathrm{sb}}+\dot{A}_{\mathrm{bw}}}{\mathrm{A}_{\mathrm{wl}}}\right)\left(1-\mathrm{F}_{\mathrm{b}}+\rho_{b w} W_{b w-\mathrm{wl}} F_{b}\right) \mathrm{G}_{\mathrm{bh}}$

For diffuse radiation, solar energy intercepted by the water is given by:

$\mathrm{A}_{\mathrm{wl}} \mathrm{G}_{\mathrm{de}}=\mathrm{A}_{\mathrm{wl}} \mathrm{W}_{\mathrm{wl}-\mathrm{sk}} \mathrm{G}_{\mathrm{dh}}+\rho_{\mathrm{bw}} \mathrm{A}_{\mathrm{bw}} \mathrm{W}_{\mathrm{bw}-\mathrm{wl}} \mathrm{W}_{\mathrm{bw}-\mathrm{sk}} \mathrm{G}_{\mathrm{dh}}$

Using Eqs.(6-8) and (11), the effective diffuse radiation is:

$\mathrm{G}_{\mathrm{de}}=\left(\frac{\mathrm{A}_{\mathrm{wl}} \mathrm{W}_{\mathrm{wl}-\mathrm{sk}}+\mathrm{A}_{\mathrm{bw}} \mathrm{W}_{\mathrm{bw}-\mathrm{sk}}}{\mathrm{A}_{\mathrm{wl}}}\right)\left(1-\mathrm{F}_{\mathrm{d}}+\rho_{b w} \mathrm{~W}_{\mathrm{bw}-\mathrm{wl}} \mathrm{F}_{\mathrm{d}}\right) \mathrm{G}_{\mathrm{dh}}$

The total effective solar irradiance inside the still is calculated from Eqs. (10) and (12):

$\mathrm{G}_{\mathrm{ge}}=\mathrm{G}_{\mathrm{be}}+\mathrm{G}_{\mathrm{de}}$

All view factors for pairs of the internal surfaces of the still are computed according to

Incropera et al (2007). It is assumed that the two trapezoidal surfaces on the eastern and western sides of the solar still are rectangular in shape with breadth $\mathrm{B}_{\mathrm{bl}}$ and length
Deleted: It should nevertheless be noted that the water surface $\left(\mathrm{A}_{\mathrm{wl}}=\mathrm{L}_{\mathrm{bl}} \mathrm{B}_{\mathrm{bl}}\right)$ and the back wall $\left(\mathrm{A}_{\mathrm{bw}}=\mathrm{L}_{\mathrm{b}} \mathrm{Z}_{\mathrm{bw}}\right)$ have a common length.

Deleted: $\mathrm{F}_{d}=\frac{\mathrm{A}_{\mathrm{bw}} V}{\mathrm{~A}_{\mathrm{wal}} W_{w l-s k}}$

Formatted: English (U.S.), Lowered by $15 \mathrm{pt}$

\section{Deleted: $q$}

Deleted: $\mathrm{A}_{\mathrm{wl}} \mathrm{G}_{\mathrm{be}}=\mathrm{A}_{\mathrm{sb}} \mathrm{G}_{\mathrm{t}}$

Formatted: Subscript

Deleted:

Formatted: Subscript

Formatted: Subscript

Formatted: Subscript

Formatted: Subscript

Formatted: Subscript

Formatted: Subscript

Deleted: II

Deleted: $\mathrm{G}_{\mathrm{be}}=\left(1-\frac{Z_{f w} \mathrm{c}}{B_{b}}\right.$

Formatted: Lowered by $16 \mathrm{pt}$

Deleted:

Deleted: $\mathbb{I}$

Formatted: English (U.S.)

Formatted: Lowered by $16 \mathrm{pt}$

Deleted: II

$\mathrm{G}_{\mathrm{de}}=\left(\mathrm{W}_{\mathrm{wl}-\mathrm{sk}}+\frac{Z_{b w} \mathrm{~W}_{\mathrm{bw}}}{\mathrm{B}_{\mathrm{bl}}}\right.$

Deleted: 
$0.5\left(\mathrm{Z}_{\mathrm{bw}}+\mathrm{Z}_{\mathrm{fw}}\right)$. In addition, all the surfaces are treated as diffuse reflectors. Duffie and

Beckman (1991) report that the proportion of the sky viewed by a tilted surface is

$0.5(1+\cos \beta)$, in the absence of any other obstruction. Based on this, $\mathrm{W}_{\mathrm{wl}-\mathrm{sk}}$ and $\mathrm{W}_{\mathrm{bw}-\mathrm{sk}}$ are calculated as follows:

$\mathrm{W}_{\mathrm{wl}-\mathrm{sk}}=0.5\left(1+\cos \beta_{\mathrm{wl}}\right)-\left(\mathrm{W}_{\mathrm{wl}-\mathrm{bw}}+\mathrm{W}_{\mathrm{wl-ew}}+\mathrm{W}_{\mathrm{wl}-\mathrm{fw}}+\mathrm{W}_{\mathrm{wl-ww}}\right)$

$\mathrm{W}_{\mathrm{bw}-\mathrm{sk}}=0.5\left(1+\cos \beta_{\mathrm{bw}}\right)-\left(\mathrm{W}_{\mathrm{bw}-\mathrm{ew}}+\mathrm{W}_{\mathrm{bw}-\mathrm{fw}}+\mathrm{W}_{\mathrm{bw}-\mathrm{ww}}\right)$

It should be mentioned that $\mathrm{W}_{\mathrm{bw}-\mathrm{ew}}=\mathrm{W}_{\mathrm{bw}-\mathrm{ww}}$ (by symmetry) and the surface of saline water is horizontal $\left(\beta_{\mathrm{wl}}=0^{\circ}\right)$ with the back wall being vertical $\left(\beta_{\mathrm{bw}}=90^{\circ}\right)$.

\section{Application of the model}

\subsection{System description}

Non-tracking solar collectors, including distillers, are generally inclined to the horizontal facing the Equator to optimize solar collection. Garg and Mann (1976) reported that the optimum tilt angle $(\beta)$ of the transparent cover over a conventional solar still is $10^{\circ}$ which just enables the distillate to flow downwards on the inner surface of the cover without dropping back into the basin. Nevertheless, $\beta$ also affects the transmission of solar radiation through the cover (Duffie and Beckman, 1991). So, $\beta>10^{\circ}$ is sometimes used depending on the latitude

$(\phi)$ of the site (Nafey et al., 2000). Generally, $\beta=\phi-10^{\circ}$ for summer season, $\beta=\phi$ for annual - . -

Formatted: Superscript

Formatted: Superscript performance and $\beta=\phi+10^{\circ}$ for winter season (Samee et al., 2007). Capture of solar radiation reflected from the walls of a conventional still is optimal when the length is twice the width (aspect ratio, $\mathrm{AR} \approx 2.0$ ), (El-Swify and Metias, 2002). It should be mentioned that optimization is necessary for achieving the best possible yield of distilled water. Nevertheless, non-optimal values of design parameters have been used in some of the previous work, depending on the objective of the study. Porta et al. (1997) validated their model on thermal inertia in solar distillers by using a still with $\beta=4^{\circ}$ and $A R=11.3$. Tripathi and Tiwari (2004) Formatted: Superscript used $\beta=8.8^{\circ}$ and $A R=1.0$ for a conventional still tested at a latitude of $28^{\circ} 35^{\prime} \mathrm{N}$, to validate 
their model on solar fraction. Later, an inclination angle of $\beta=10.2^{\circ}$ and $A R=1.0$ were used

for a still studied at the same location by Tripathi and Tiwari, (2006).

The objective of the present study was to develop a model that calculates the amount of

$\underline{\text { solar energy received by saline water in a single-slope solar still. This model takes into }}$

account the design and site parameters, and it was validated by using a conventional solar still

with one slope. The basin $(0.90 \mathrm{~m} \times 0.80 \mathrm{~m})$ of the test still $(\mathrm{AR}=1.1)$ was constructed from

galvanized steel (0.0008 m thick), painted gloss black on the inner surface to optimize

absorption of solar radiation and placed horizontally on polystyrene insulation inside a

Deleted: A single-slope solar still was designed with a horizontal basin.

Deleted: kness

Deleted: inside part

Deleted: and

Formatted: Superscript

wooden box (made of plywood). A glass cover $\left(0.004 \mathrm{~m}\right.$ thick, $\left.\beta=16^{\circ}\right)$ was fitted on the top part of the evaporator chamber to allow solar radiation reach the saline water in the basin. A

\section{Deleted: ,}

Deleted: tilted at $16^{\circ}$,

rectangular galvanized steel channel was fitted inside the box, on the lower edge of the glass.

The inside part of the box was painted matt black to reduce condensation of vapor on the walls while the exterior part of the box was painted gloss light green to protect the wooden structure from weathering. Details of the system design and operating parameters are presented in Table 1.

Formatted: Font color: Black

\subsection{Heat balance equations}

_Heat balance equations were formulated to predict the performance of the solar still. The effective solar irradiance, computed using the previous (Tripathi and Tiwari, 2004) and present solar fraction models were used in these equations. It was assumed that:

a) solar radiation absorbed by the walls is negligible;

b) the solar still is air-tight; and

c) there is no leakage of vapour and condensate.

With these assumptions, the heat balance equations for the still are:

Glass cover $(\mathrm{gc})$ 


$$
\begin{aligned}
& m_{g c} C_{p, g c} \frac{d T_{g c}}{d t}=A_{g c} f_{g c} G_{g e}+A_{w l} h_{g c}\left(T_{w l}-T_{g c}\right)-A_{g c} h_{c, g c-a}\left(T_{g c}-T_{a}\right)-h_{r, g c-s k}\left(T_{g c}-T_{s k}\right) \\
& h_{g c}=\left(h_{c, w l-g c}+h_{e, w l-g c}+h_{r, w l-g c}\right)
\end{aligned}
$$

Basin liner (bl)

$$
m_{b l} C_{p, b l} \frac{d T_{b l}}{d t}=A_{w l}\left\{f_{b l} G_{g e}-h_{c, b l-w l}\left(T_{b l}-T_{w l}\right)-U_{b o}\left(T_{b l}-T_{a}\right)\right\}
$$

Water in basin (wl)

$$
\begin{aligned}
& m_{w l} C_{P, w l} \frac{d T_{w l}}{d t}=A_{w l}\left[f_{w l} G_{g e}+h_{c, b l-w l}\left(T_{b l}-T_{w l}\right)\right]-A_{w l} h_{w l}\left(T_{w l}-T_{g c}\right)-A_{s w} U_{s w}\left(T_{w l}-T_{a}\right) \\
& h_{w l}=h_{c, w l-g c}+h_{e, w l-g c}+h_{r, w l-g c}
\end{aligned}
$$

Rate of condensation (dw)

$$
\frac{d m_{d w}}{d t}=\frac{h_{e, w l-g c}\left(T_{w l}-T_{g c}\right)}{H_{w l}}
$$

The distillate yield $(\mathrm{Y})$ in a time interval of $\left(\mathrm{t}_{2}-\mathrm{t}_{1}\right)$ is calculated as follows:

$$
Y=\int_{t_{1}}^{t_{2}}\left[\frac{h_{e, w l-g c}\left(T_{w l}-T_{g c}\right)}{H_{w l}}\right] d t
$$

\subsection{Solution procedure}

_ The values of the absorptance factor (f) were computed as follows, taking into account the angular dependence of the optical properties of the glass cover (Duffie and Beckman, 1991):

$$
\begin{aligned}
& f_{g c}=\alpha_{g c} \\
& f_{w l}=\alpha_{w l}\left(1-\alpha_{g c}-\rho_{g c}\right) \\
& f_{b l}=\alpha_{b l}\left[1-\alpha_{g c}-\rho_{g c}-\rho_{w l}\left(1-\alpha_{g c}-\rho_{g c}\right)-f_{w l}\right]
\end{aligned}
$$

Heat loss from the top of the glass cover to the environment is predominantly by convection (to ambient air) and radiation (to sky). Wind influencing the convective heat transfer from the top part of the cover and the wind coefficient of heat transfer is calculated from (Wattmuf et al., 1977): 
$h_{c, g c-a}=\left\{\begin{array}{l}2.8+3 V_{w d}, V_{w d} \leq 5 m s^{-1} \\ 6.15 V_{w d}^{0.8}, V_{w d}>5 m s^{-1}\end{array}\right.$

The coefficient of radiative heat transfer is referenced to the sky and computed from (Duffie and Beckman, 1991):

$$
h_{r, g c-s k}=\sigma \varepsilon_{g c}\left(T_{g c}^{2}+T_{s k}^{2}\right)\left(T_{g c}+T_{s k}\right)
$$

where the sky temperature is given by (Sharma and Mullick, 1991):

$$
\left.T_{s k}=0.0552 T_{a}^{2}\right)
$$

The evaporation and condensation processes involve the transfer of both heat and mass.

Consequently, relevant correlations are required to estimate the coefficients of internal

Deleted: used convective and evaporative heat transfers from hot water to the glass cover surfaces. Several authors, including Lawrence et al. (1990), Fath and Elsherbiny (1993), Tripathi and Tiwari (2004), Tanaka and Nakatake (2006) used the heat and mass transfer correlations proposed by Dunkle (1961). These correlations are accurate for predicting the performance of solar stills of Deleted: Deleted: (Dunkle, 1961) the conventional variety (Tsilingiris). In view of this, the coefficients of convective and evaporative heat transfer used in the present study are based on Dunkle's model:

$$
\begin{aligned}
h_{c, w-c s} & =0.884\left[\left(T_{w}-T_{c s}\right)+\frac{\left(P_{w}-P_{c s}\right) T_{w}}{268900-P_{w}}\right]^{1 / 3} \\
h_{e, w-c s} & =\frac{0.016273 h_{c, w-c s}\left(P_{w}-P_{c s}\right)}{T_{w}-T_{c s}}
\end{aligned}
$$

In addition, there is internal radiative transfer from hot water to the glass cover. The coefficient of internal radiative heat transfer is estimated from (Duffie and Beckman, 1991):

$$
\begin{aligned}
& h_{r, w l-g c}=\sigma \varepsilon_{w l-g c}\left(T_{w l}^{2}+T_{g c}^{2}\right)\left(T_{w l}+T_{g c}\right) \\
& \varepsilon_{w l-c s}=\left(\frac{1}{\varepsilon_{w l}}+\frac{1}{\varepsilon_{c s}}-1\right)^{-1}
\end{aligned}
$$


There is heat loss from the bottom and side walls of the still. In this study, the coefficient of bottom heat loss was calculated from (Duffie and Beckman, 1991):

$$
\mathrm{U}_{\mathrm{bo}}=\left(\frac{\mathrm{x}_{1}}{k_{1}}+\frac{\mathrm{x}_{2}}{k_{2}}\right)^{-1}
$$

while the coefficient of heat loss from the sides was estimated from:

$\mathrm{U}_{\mathrm{sw}}=\frac{\mathrm{k}_{2}}{x_{2}}$

The coefficient of heat transfer from the basin liner to the saline water $\left(\mathrm{h}_{\mathrm{c}, \mathrm{bl}-\mathrm{wl}}\right)$ was taken to be $100 \mathrm{Wm}^{-2} \mathrm{~K}^{-1}$, (Tripathi and Tiwari, 2004, 2006) while the values of the physical properties used in the present study are: $C_{p, g c}=750 \mathrm{~J} \mathrm{~kg}^{-1} \mathrm{~K}^{-1}, \mathrm{C}_{\mathrm{p}, \mathrm{wl}}=4190 \mathrm{Jkg}^{-1} \mathrm{~K}^{-1}, \mathrm{C}_{\mathrm{p}, \mathrm{bl}}=477 \mathrm{Jkg}^{-1} \mathrm{~K}^{-1}$, $\alpha_{\mathrm{wl}}=0.05, \rho_{\mathrm{wl}}=0.02, \rho_{\mathrm{wa}}=0.05, \sigma=5.67 \times 10^{-8} \mathrm{Wm}^{-2} \mathrm{~K}_{\mathrm{v}}^{-4}, \varepsilon_{\mathrm{gc}}=0.88$ and $\varepsilon_{\mathrm{w}}=0.96$. At normal incidence, the values of $\alpha_{\mathrm{gc}}$ and $\rho_{\mathrm{gc}}$ were taken to be 0.10 and 0.12 respectively. It was assumed that the basin liner was made of galvanized iron sheet. The specific latent heat of water vaporization $(\mathrm{H})$ was calculated using a correlation reported by Belessiotis et al. (1995) while the saturation vapour pressure (P) was calculated according to ASHRAE (2001). , _A computer program was written in MATLAB (version 7.0) to solve the above system of non-linear equations using the Gauss-Seidel explicit iterative method (Burden and Faires, 1985), with a temperature tolerance of $0.5 \mathrm{~K}$ and time step of 20s. Solar altitude and azimuth angles were computed according to Duffie and Beckman (1991). These angles were used to determine the projected area of the back wall, the area of the water receiving solar radiation directly, the solar fraction on the wall and the corresponding effective beam and diffuse solar irradiance. Values of the effective irradiance, ambient temperature and wind speed were used to predict the performance of the still. Initial values for the temperatures of the system components were assumed to be approximately equal to $T_{a}$. Based on these values of temperature and physical properties, appropriate coefficients of heat transfer (assumed 
constant in a given time step) were calculated for estimating temperatures in the next time step (Fig.3).

\subsection{Measurements}

_ The system was mounted outdoors, facing south $(\gamma=0)$, on steel frames on top of a horizontal roof $35 \mathrm{~m}$ above the ground to reduce shading from tall structures at the University of Strathclyde $\left(55^{\circ} 52^{\prime} \mathrm{N}, 4^{\circ} 15^{\prime} \mathrm{W}\right)$. The basin was filled with $20 \mathrm{~kg}$ of tap water, and topped up once in the morning on every test day

_ Two Kipp \& Zonen pyranometers (model CM 11, error of $3 \%$ ) were used to measure global $\left(\mathrm{G}_{\mathrm{gh}}\right)$ and diffuse $\left(\mathrm{G}_{\mathrm{dh}}\right)$ irradiance on a horizontal surface. For diffuse irradiance, the pyranometer was placed under a Kipp \& Zonen shadow ring (model CM 121B) and the recorded data was corrected for the shadow ring (Kipp \& Zonen, 2004). It should be mentioned that the shadow ring is part of the existing instrumentation in a weather station located on the roof of the building in which the Department of Mechanical Engineering is accommodated at the University of Strathclyde. Irradiance at various selected points inside $\underline{\text { the solar still was not measured due to the limitation of radiometers. Moreover, the area }\left(\mathrm{A}_{\mathrm{s}} \text { ) }\right.}$ of saline water that directly receives beam radiation is dynamic which would lead to a $\underline{\text { significant variation amongst the values of irradiance recorded at different locations within }}$ the distiller during certain times of the day. The temperature of water and other components was determined by using T-type thermocouples $( \pm 0.5 \mathrm{~K})$. Five thermocouples were inserted into saline water within the basin (one thermocouple in the middle, and one in each corner of the evaporator basin). Similarly, the temperature of the glass cover was also measured using five shielded thermocouples. Wind speed was measured by a Vector Instruments anemometer (model A100L2, error of $1 \%$ ) during the experimental period. All these sensors were connected to a Delta-T Devices Ltd data logger (model DL2e) with sampling and logging at 
intervals of $10 \mathrm{~s}$ and $300 \mathrm{~s}$ respectively. The distillate mass was measured by using a Jadever Scale Ltd digital top-loading balance (model JB-6000) with a readability of $0.001 \mathrm{~kg}$.

\subsection{Data processing}

_In any given logging time interval, the beam and diffuse solar fractions were computed from the geometry of the still, latitude and longitude of the site, and the solar azimuth and altitude angles of the sun at the midpoint of the time interval. To avert errors in computation of effective solar radiation at low solar altitude, the astronomical duration between sunrise and

sunset was shortened by 7200 s, (Cooper, 1969).

_ The beam solar irradiance $\left(\mathrm{G}_{\mathrm{bh}}\right)$ on a horizontal surface was calculated from measured values of $\mathrm{G}_{\mathrm{gh}}$ and $\mathrm{G}_{\mathrm{dh}}$.

$\mathrm{G}_{\mathrm{bh}}=\mathrm{G}_{\mathrm{gh}}-\mathrm{G}_{\mathrm{dh}}$

For the previous model (Tripathi and Tiwari, 2004), the effective global irradiance was determined as follows:

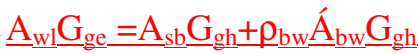

$\mathrm{G}_{\mathrm{ge}}=\left(\frac{\mathrm{A}_{\mathrm{sb}}+\dot{\mathrm{A}}_{\mathrm{bw}}}{\mathrm{A}_{\mathrm{wl}}}\right)\left(1-\mathrm{F}_{\mathrm{b}}+\rho_{b w} F_{b}\right) \mathrm{G}_{\mathrm{gh}}$

Finally, the mean bias error (MBE), root mean square error (RMSE) and t-statistic were computed according to Stone (1993).

Deleted: using Eq.(36)

Deleted: :

Formatted: Lowered by $16 \mathrm{pt}$ Deleted: II

$\mathrm{G}_{\mathrm{ge}}=\left(\frac{\mathrm{A}_{\mathrm{sb}}+\mathrm{A}_{\mathrm{pw}}}{\mathrm{A}_{\mathrm{wl}}}\right)(1-\mathrm{F}$

Deleted: 6

Deleted: II

Deleted: II

II

\section{Results}

\subsection{Meteorological conditions}

_Fig.4 shows the variation of weather on $17^{\text {th }}$ October 2007. It is observed that beam irradiance was higher than diffuse irradiance during the most part of the day. The irradiance was intermittent especially around solar noon but the observed levels are satisfactory for a site at high altitude in the northern hemisphere during the month of October. It should be 
mentioned that solar radiation is the most influential environmental parameter in distillate productivity (Nafey et al., 2000). Distillate production increases with irradiance _ It is seen that ambient air temperature was relatively low, varying between 280 and $287 \mathrm{~K}$ during the test period. Distillate production tends to increase with temperature (Cooper, 1969; Nafey et al., 2000). Consequently, production of distilled water would also be adversely affected on the typical day in spite of satisfactory levels of solar radiation. The speed of wind $\left(\mathrm{V}_{\mathrm{wd}}\right)$ varied between 0.2 and $7.8 \mathrm{~ms}^{-1}$. Generally, wind speeds exceeded $4.0 \mathrm{~ms}^{-1}$ from 9:00hrs to $16: 00 \mathrm{hrs}$. On other test days, wind speeds exceeding $10 \mathrm{~ms}^{-1}$ were recorded during certain times. El-Sebaii (2004) found that still productivity decreased with increasing $\mathrm{V}_{\mathrm{wd}}$ until a typical wind speed was reached, for water masses $\left(\mathrm{m}_{\mathrm{wl}}\right)$ less than $45 \mathrm{kgm}^{-2}$. Distillate production would again be adversely affected by the levels of wind speed because $\mathrm{m}_{\mathrm{wl}}=28 \mathrm{kgm}^{-2}$ in the present study.

\subsection{Solar fraction}

_The variation of beam $\left(F_{b}\right)$ and diffuse $\left(F_{d}\right)$ solar fractions with time is shown in Fig.5. The beam solar fraction varied significantly with a minimum at around solar noon. This indicates that the beam solar fraction is most significant at low altitude angles of the sun, consistent with findings of Tripathi and Tiwari $(2004,2006)$. It should also be noted that $F_{b}$ is not changing intermittently with the time of the day, as expected from Eq.(5). In contrast, the diffuse solar fraction does not vary with the time of the day, probably due to its sole dependence on the geometric factors of the still. The areas and view factors in Eq.(8) are constant for a given design. In addition, the diffuse solar fraction is lower than the beam solar fraction on the typical day. Again, $F_{d}$ is not intermittent because of Eq.(8).

_ It is evident that $F_{b}$ and $F_{d}$ have different characteristics, and the use of the same solar fraction for beam and diffuse solar radiation would therefore lead to incorrect estimations of distillate productivity from a single-slope solar still. At any given time of the day, the
Deleted: 1

Deleted: to

Deleted: $\mathrm{V}_{\mathrm{wd}}>$ 
calculated values of the beam and diffuse solar fractions were employed in computing the corresponding effective beam and diffuse irradiances inside the still.

\subsection{Effective irradiance}

_Fig.6 shows the variation of the effective beam $\left(G_{b e}\right)$ and diffuse $\left(G_{d e}\right)$ irradiance with time on a typical day. It is seen that the effective beam irradiance is consistently lower than the observed values, due to the fact that some of the beam radiation transmitted by the glass cover does not reach the surface of the water. It should also be noted that intermittency in the observed beam irradiance is replicated in the effective beam irradiance. Similarly, it is seen that the effective diffuse irradiance is lower than observed levels. It is also seen that intermittency in the observed diffuse irradiance is replicated in the effective diffuse irradiance.

Fig.7 shows the variation of the total effective $\left(\mathrm{G}_{\mathrm{ge}}\right)$ and observed irradiances $\left(\mathrm{G}_{\mathrm{gh}}\right)$ on a typical day. It is observed that the previous model yields higher values of $\mathrm{G}_{\mathrm{ge}}$ than the present model during the most part of the day, probably due to the influence of solar fractions and optical view factors. The previous model uses the same solar fraction for beam and diffuse irradiance. However, it has been shown in Section 4.2 that the beam and diffuse solar fractions have significantly different characteristics. In addition, the previous model does not take into consideration the view factors of surfaces that exchange solar radiation. The back wall reflects $\rho_{\mathrm{bw}}$ of the available solar energy onto the surface of water in the previous model (Eqs. $3 \underline{6 \text { and } 37)}$ while the wall effectively reflects $\left(\rho_{\mathrm{b} w} \mathrm{~W}_{\mathrm{bw}-\mathrm{wl}}\right)$ of the intercepted solar energy in the new model (Eqs.10 and 12). In the present design, $\rho_{\mathrm{bw}}=0.05$ and $\left(\rho_{\mathrm{bw}} \mathrm{W}_{\mathrm{bw}-\mathrm{wl}}=0.0145\right)$, which indicates that the previous model would overestimate radiation exchange between the back wall and water surface. Throughout the day, the water surface and back wall directly receive constant proportions of 0.53 and 0.23 of the diffuse radiation measured on a horizontal surface respectively (Table 1$)$. It is also seen that the global irradiance $\left(\mathrm{G}_{\mathrm{gh}}\right)$

\begin{tabular}{l} 
Deleted: Moreover, $\mathrm{t}$ \\
Deleted: view 0.53 and 0.23 of \\
the sky respectively. Thus, the \\
water and the back wall \\
Deleted: 5 \\
\hline Deleted: $\%$ \\
\hline Deleted: $\%$ \\
\hline
\end{tabular}


measured on a horizontal surface outside the still is significantly higher than the effective total irradiance. This shows that the use of $\mathrm{G}_{\mathrm{gh}}$ in the heat balance equations would lead to overestimation of the solar load on the saline water.

\subsection{Model performance}

Fig. 8 shows the variation of estimated and measured hourly distillate yield. It is observed that both the previous and the present models slightly overestimate the yield, which is ascribed to possible vapour and distillate leakage from a practical solar still. However, the previous model provides higher estimates of the distillate yield than the present model, consistent with the computed effective irradiances. The distillate estimates provided by the new model are closer to the measured data. It should be noted that the hourly production is relatively small due to low insolation levels, which make it difficult to measure the hourly mass of distilled water with sufficient accuracy. So, the daily distillate yield was found to be more accurate for statistical analysis.

Results of the statistical analysis of the daily yield for 22 days are presented in Table 2 . It is observed that both the previous and present models slightly overestimate the production of distilled water (MBE $>0$ ), as expected. Further, the RMSE for the previous model is higher than that of the present one. Finally, the t-statistic for the previous model is higher than that for the present model. Stone (1993) reported that a model with a smaller value of the tstatistic performs better than the one with a higher value. These observations indicate that the performance of the new model is satisfactory.

\section{Conclusion}

A new model that calculates the distribution of solar radiation in a single-slope solar still has been proposed. In this model, the solar fraction on a wall is divided into beam and diffuse parts and the optical view factors of surfaces inside the still are taken into account. The

\section{Deleted: $q$}

4.4 Sensitivity analysis I a) Optical view factorsđI Optical view factors influence the exchange of radiation between two given surfaces, and these factors depend on the geometries of the surfaces in question. In this section, the effect of varying the length $\left(\mathrm{L}_{\mathrm{bl}}\right)$, width $\left(\mathrm{B}_{\mathrm{b}}\right)$ and height of the back wall $\left(\mathrm{Z}_{\mathrm{bw}}\right)$ of the solar still on the view factors that appear in equations for calculating the diffuse solar fraction (Eq.8), effective beam (Eq.10) and diffuse (Eq.12) irradiances are presented. If II

Table 2 shows the effects of $\mathrm{L}_{b}$, $B_{b 1}$ and $Z_{b w}$ on the optical view factors of the back wall relative to the sky ( $\mathrm{W}_{\text {bw-sk }}$ ), back wall relative to the water surface $\left(\mathrm{W}_{\mathrm{bw}-\mathrm{w}}\right)$ and water surface with respect to the sky $\left(\mathrm{W}_{\mathrm{wl-sk}}\right)$. It is observed that all the view factors $\mathrm{W}_{\mathrm{bw}-\mathrm{sk}}, \mathrm{W}_{\mathrm{bw}-\mathrm{wl}}$ and $\mathrm{q}$ $\mathrm{W}_{\text {wl-sk }}$ increase with the length of the still, probably due to increases in the areas of the surface of water and back wall. This shows that the proportions of diffuse solar

radiation directly received by the back wall and water surface, and the fraction of beam and diffuse solar energy reflected from the back wall onto the water surface would increase with the length of the solar still. If

II It is also seen that that the view factors $\mathrm{W}_{\mathrm{bw}-\mathrm{wl}}$ and $\mathrm{W}_{\mathrm{wl}-\mathrm{sk}}$ increase while $\mathrm{W}_{\mathrm{bw}-\mathrm{sk}}$ does not significantly change with the width of the solar still. This trend is attributed to an increase in the area of water for a given area of the back wall. These results show that the amount of diffuse radiation directly received by the water surface would increase with the width of the still while the proportion of diff $\ldots$ [1]

Deleted: 5

Deleted: Fig.14 shows the variation of the estimated and measured temperatures of the glass cover $\left(\mathrm{T}_{\mathrm{gc}}\right)$ and water in the basin $\left(\mathrm{T}_{\mathrm{wl}}\right)$ with time on a typical day.

For the glass temperature, it is observed that $\mathrm{T}_{\mathrm{gc}}$ is intermi ... [2]

Deleted: 15

Deleted: $\mathbb{I}$

Deleted: Fig.16 shows the variation of the daily distillate yield on 22 test days. It is seen that there is reasonable agreement between estimated and measured data for both the previous and present models. However, t ... [3]

Deleted: 3

Deleted: daily

Deleted: $q$ 
present model was applied to a solar still with one slope tested outdoors under different weather conditions. It is found that the beam solar fraction is affected by both the geometry of the still and the position of the sun in the sky. In contrast, the diffuse solar fraction depends solely on the geometry of the distiller. The new model performs better than the previous one on solar fraction. It appears that splitting the solar fraction into beam and diffuse parts improves the accuracy of modelling the performance of a solar still with a single slope.

\section{Nomenclature}

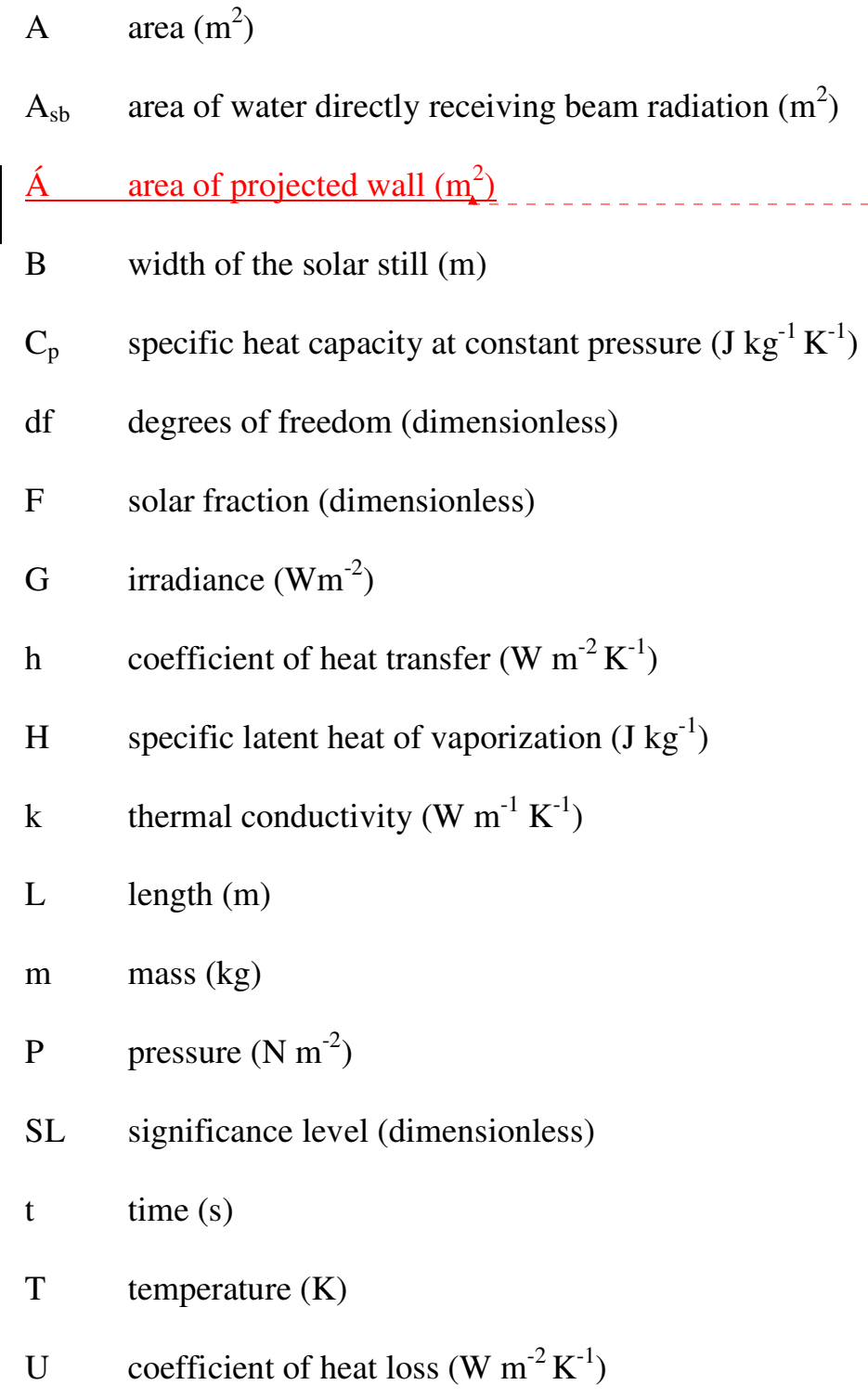




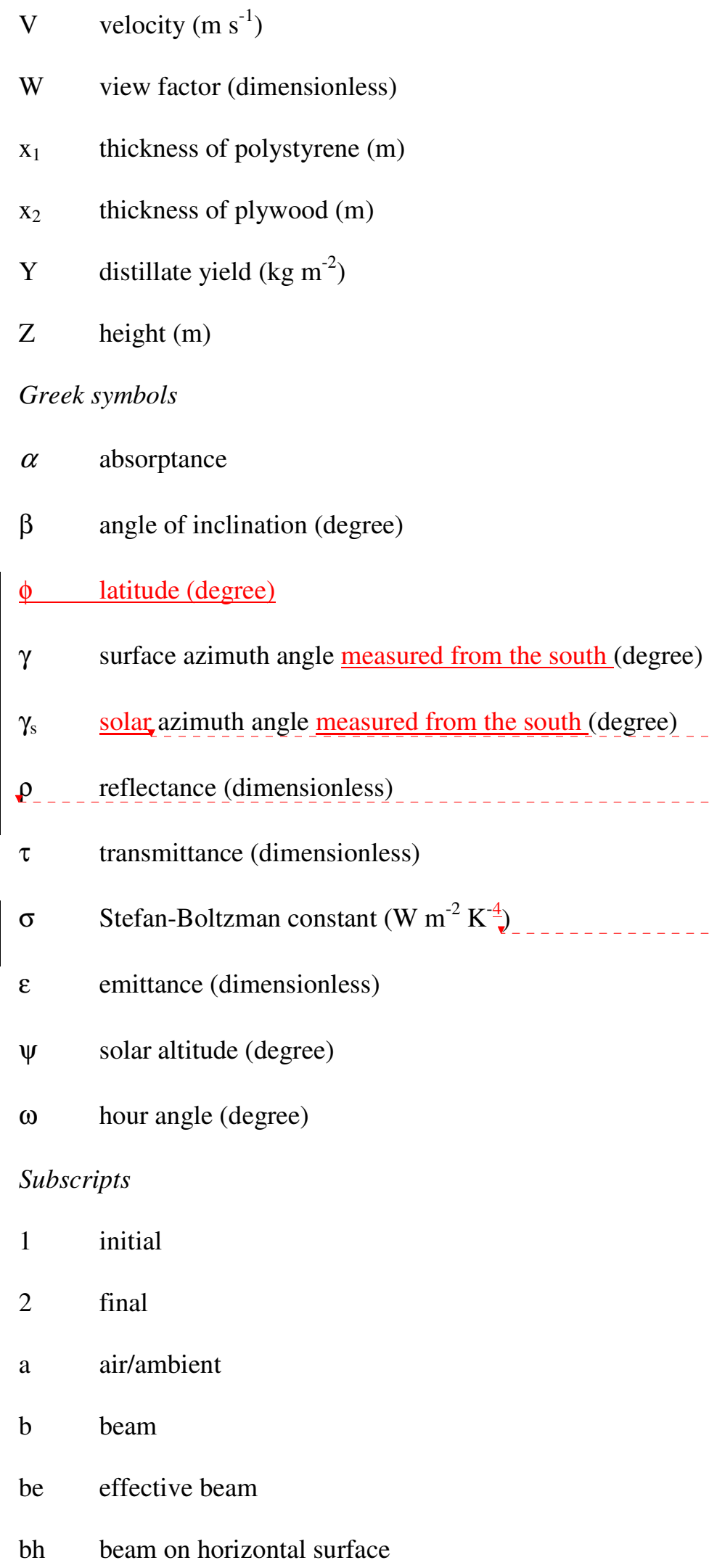




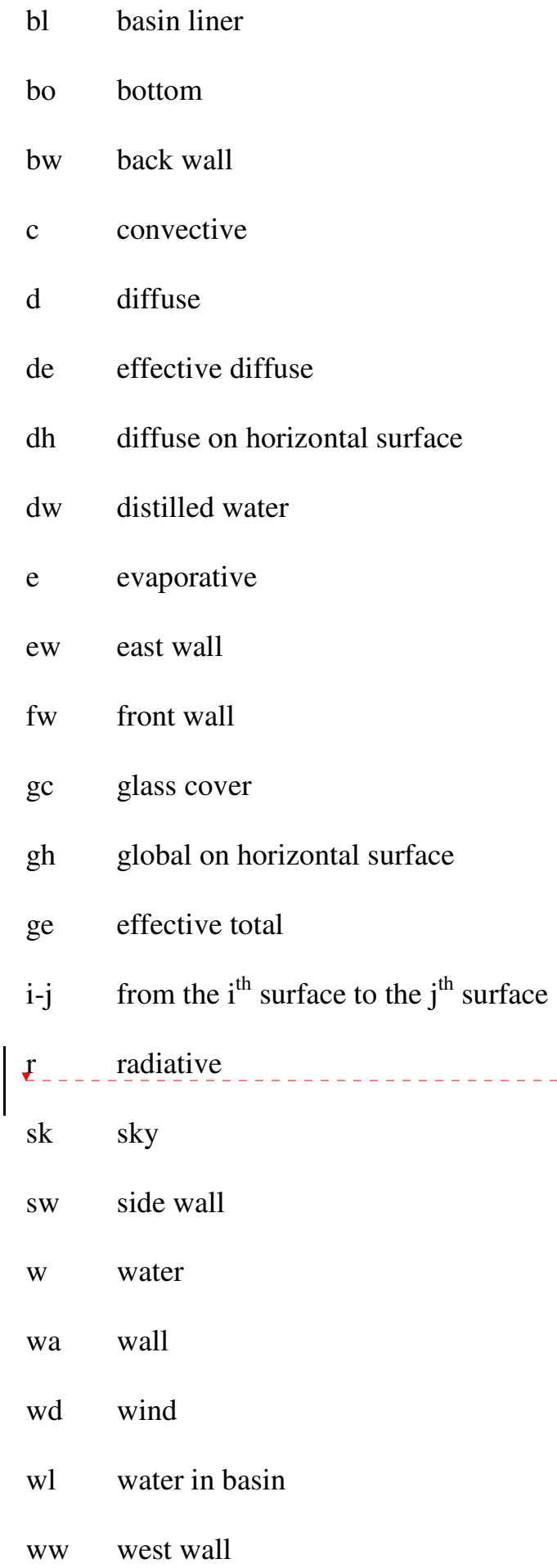




\section{Acknowledgements}

The authors are very grateful to the Commonwealth Scholarship Commission for the financial support. The Centre for Water, Sanitation, Health and Technology Development

(WASHTED) at the Malawi Polytechnic, and Universities of Strathclyde and Malawi are also acknowledged for the various forms of support.
Deleted: The University of Strathclyde is also acknowledged for the provision of various forms

of support. II

Formatted: Font: Bold

Al-Kharabsheh, S., Goswami, D.Y., 2003. Experimental study of an innovative solar water desalination system utilizing a passive vacuum technique. Solar Energy 75, 395-401.

ASHRAE, 2001. Fundamentals Handbook. American Society of Heating, Refrigerating And Air-Conditioning Engineers, Atlanta

Deleted: $\mathbb{1}$

Belessiotis, V., Voropoulos, E., Delyannis, E., 1995. Experimental and theoretical method for determination of the daily output of a still: input-output method. Desalination 100, 99-104. Bouchekima, B., Gros, B., Oahes, R., Diboun, M., 1998. Performance study of the capillary film solar distiller. Desalination 116, 185-192.

Burden, R.L., Faires, J.D., 1985. Numerical Analysis, $3^{\text {rd }}$ ed. PWS Publishers, Boston.

Cooper, P.I., 1969. The absorption of radiation in solar stills. Solar Energy 12,

Formatted: French (France) Formatted: Indent: First line: $0 \mathrm{~cm}$, Line spacing: Double Formatted: English (U.S.) Formatted: English (U.S.) Formatted: Line spacing: Double

Formatted: English (U.S.) 333-346

Cooper, P.I., 1973. The maximum efficiency of single-effect solar stills. Solar Energy 15, 205-217.

Delyannis, E., 2003. Historic background of desalination and renewable energies. Solar Energy $75,357-366$.

Duffie, J.A., Beckman, W.A.,__1991. Solar Engineering of Thermal Processes, $2^{\text {nd }}$ ed.

New York:Wiley Interscience, 
Dunkle, R.V., 1961. Solar water distillation: the roof type still and a multiple effect diffusion still. International Development in Heat Transfer. International Heat Transfer Conference, University of Colorado, pp.895-902 (part 5).

El-Swify, M.E., Metias, M.Z., 2002. Performance of double exposure solar still. Renewable Formatted: Indent: Left: 0 $\mathrm{cm}$ Energy 26, 531-547.

El-Sebaii, A.A., 2004. Effect of wind speed on active and passive solar stills. Energy Conversion and Management 45,_1187-1204.

Fath, H.E.S., Elsherbiny, S.M., 1993. Effect of adding a passive condenser on solar still Formatted: Indent: Left: 0 $\mathrm{cm}$ performance. Energy Conversion and Management 34, 63-72.

Fritzmann, C., Löwenberg, J., Wintgens, T., Melin, T., 2007. State-of-the-art of reverse osmosis desalination. Desalination 216, 1-76.

Garg, H.P., Mann, H.S., 1976. Effect of climatic, operational and design parameters on the year round performance of single-sloped and double-sloped solar still

Formatted: English (U.S.)

Formatted: French (France) Formatted: Indent: First line: $1.27 \mathrm{~cm}$

Deleted: under Indian arid zone conditions. Solar Energy 18, 159-164.

Incropera, F.P., DeWitt, D.P., Bergman, T.L., Lavine, A.S., 2007. Fundamentals of heat and mass transfer, $6^{\text {th }}$ ed. John Wiley $\&$ Sons, New Jersey.

Kipp \& Zonen, 2004. Instruction Manual: CM 121 shadow ring. Kipp \& Zonen, Delft.

Lawrence, S.A., Gupta, S.P., Tiwari, G.N., 1990. Effect of heat capacity on the performance of solar still with water flow over the glass cover. Energy Conversion and $1.27 \mathrm{~cm}$ Management 30, 277-285.

Mowla, D., Karimi, G., 1995. Mathematical modelling of solar stills in Iran. Solar Energy 55, 389-393.

Nafey, A.S., Abdelkader, M., Abdelmotalip, A., Mabrouk, A.A., 2000. Parameters affecting solar still productivity. Energy Conversion and Management 41, 1797-1809.

Porta, M.A., Chargoy, N., Fernández, J.L., 1997. Extreme operating conditions in shallow Formatted: Indent: Left: 0 $\mathrm{cm}$ solar stills. Solar Energy 61, 279-286. 
Reindl, D.T., Beckman, W.A., Duffie, J.A., 1990. Evaluation of hourly tilted surface radiation models. Solar Energy 45, 9-17.

Samee, M.A., Mirza, UK., Majeed, T., Ahmad, N., 2007. Design and performance of a simple single basin solar still. Renewable and Sustainable Energy Reviews 11, 543-549.

Sharma, V.B., Mullick, S.C., 1991. Estimation of heat-transfer coefficients, the upward heat flow, and evaporation in a solar still. ASME Journal of Solar Engineering 113:36-41.

Stone, R.J., 1993. Improved statistical procedure for the evaluation of solar radiation estimation models. Solar Energy 51, 289-291.

Tanaka, H., Nakatake, Y., 2006. Theoretical analysis of a basin type solar still with internal and external reflectors. Desalination 197, 205-216.

Tiwari, G.N., Singh, H.N., Tripathi, R., 2003. Present status of solar distillation. Solar Energy $75,367-373$.

Tiwari, A.K., Tiwari, G.N., 2007. Thermal modelling based on solar fraction and experimental study of the annual performance of a single slope passive solar still: The effect of water depths. Desalination 207, 184-204.

Tripathi, R., Tiwari, G.N., 2004. Performance evaluation of solar still by using the concept of solar fraction. Desalination 169, 69-80.

Tripathi, R., Tiwari, G.N., 2006. Thermal modeling of passive and active solar stills for different depths of water by using the concept of solar fraction. Solar

Deleted: $\mathrm{r}$ Energy 80, 956-967.

Tsilingiris, P.T., Analysis of the heat and mass transfer processes in solar stills. Solar. Energy, in press.

Wattmuf, J.H., Charters, W.W.S., Proctor, D., 1977. Solar and wind induced external coefficients for solar collectors. Compless 2, 56.

WHO, 2008. World Health Statistics 2008. World Health Organization (WHO), Geneva. 


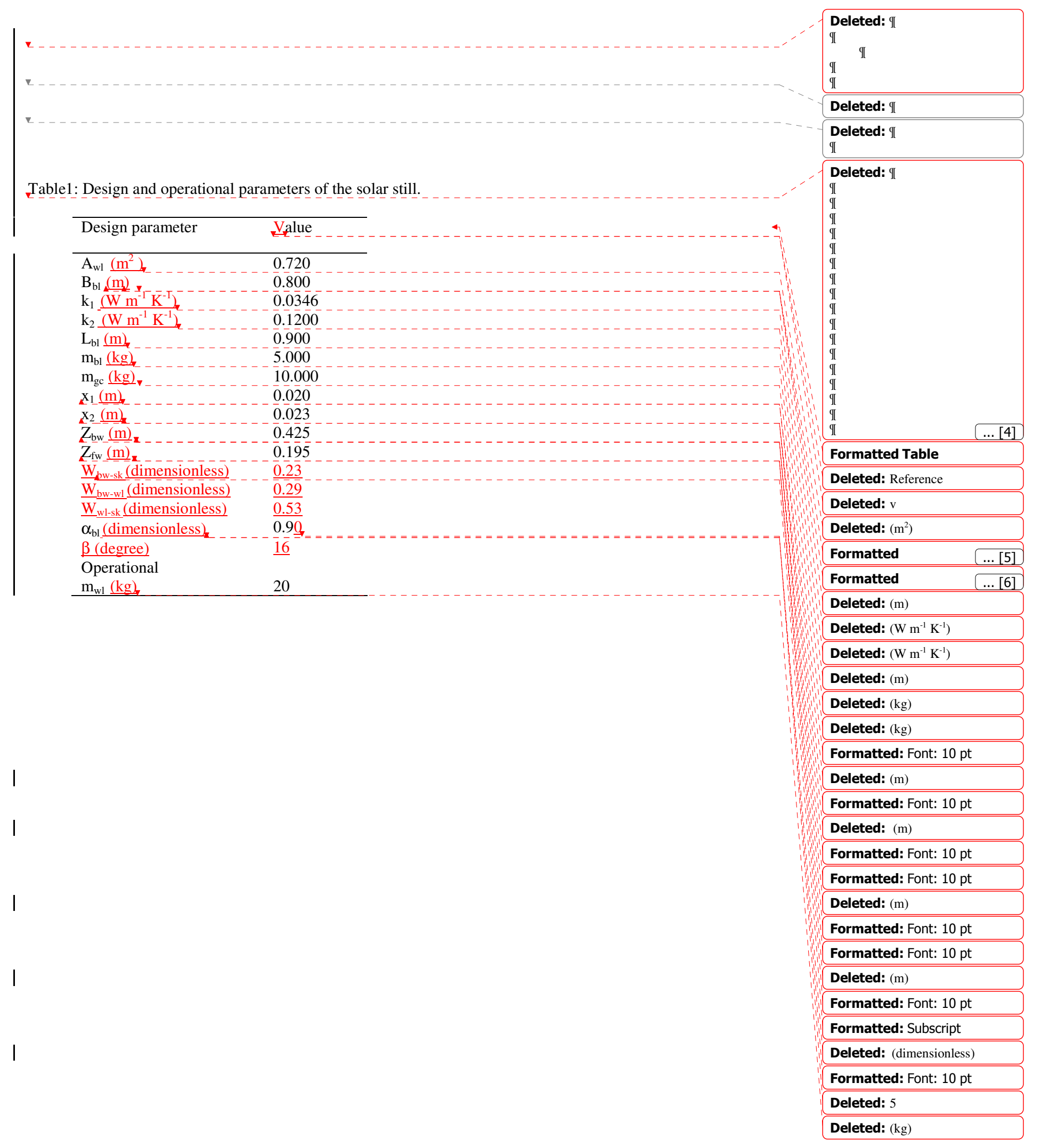

Deleted: $\mathbb{\|}$ ... [7] 


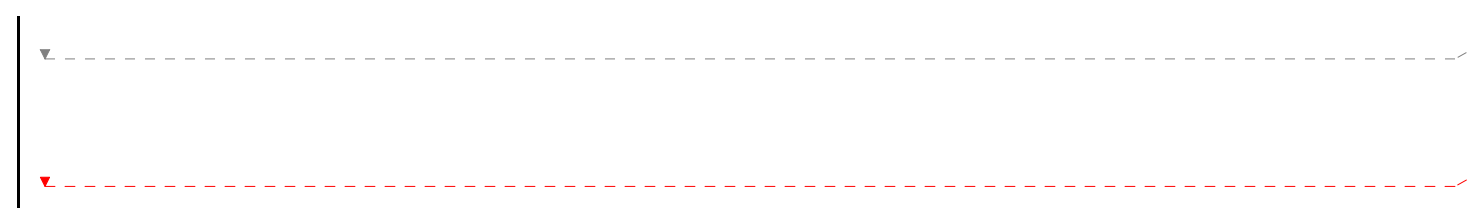

Deleted: $\mathbb{I}$

Table 2; Performance of previous and present models.

\begin{tabular}{|c|}
\hline $\begin{array}{l}\text { Deleted: } \text { II } \\
\text { II } \\
\text { II } \\
\text { II } \\
\text { II } \\
\text { II } \\
\text { II } \\
\text { II } \\
\text { II } \\
\text { II } \\
\text { II } \\
\text { II } \\
\text { II } \\
\text { I } \\
\text { II } \\
\text { II } \\
\text { II } \\
\text { II } \\
\text { II } \\
\text { II }\end{array}$ \\
\hline Deleted: 3 \\
\hline Deleted: 45 \\
\hline Deleted: 81 \\
\hline Deleted: 3.014 \\
\hline Deleted: 14 \\
\hline Deleted: 31 \\
\hline Deleted: 2 \\
\hline
\end{tabular}


Deleted: $\mathbb{I}$

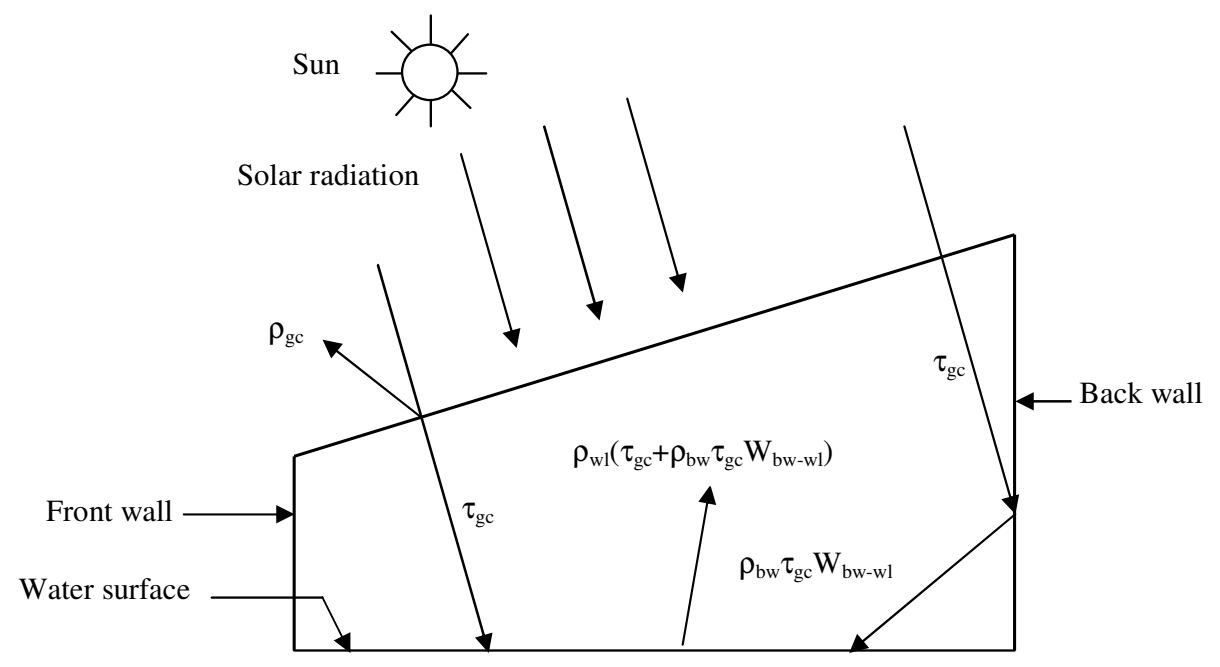

Fig.1: Distribution of solar radiation in a single slope solar still. 


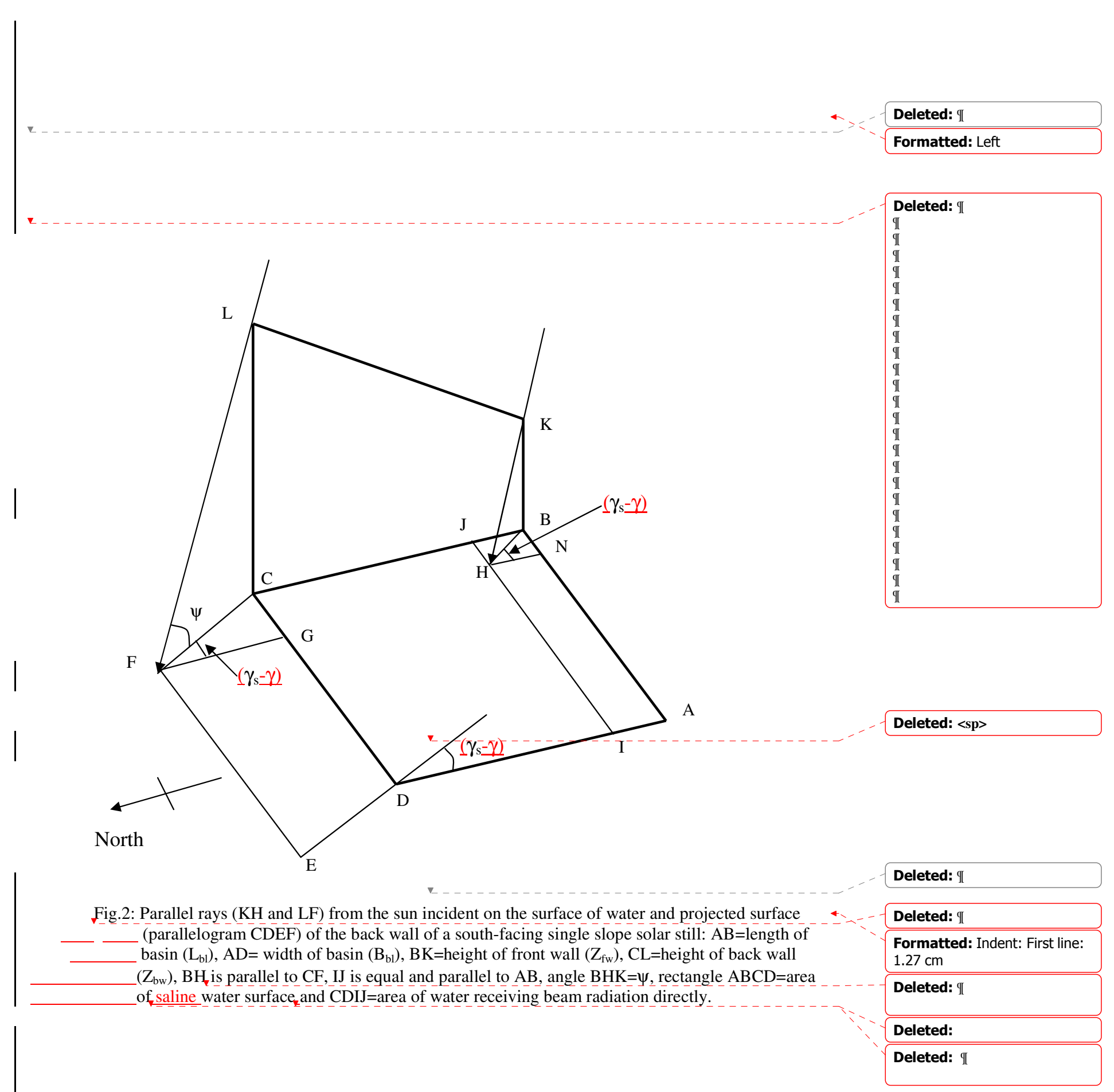




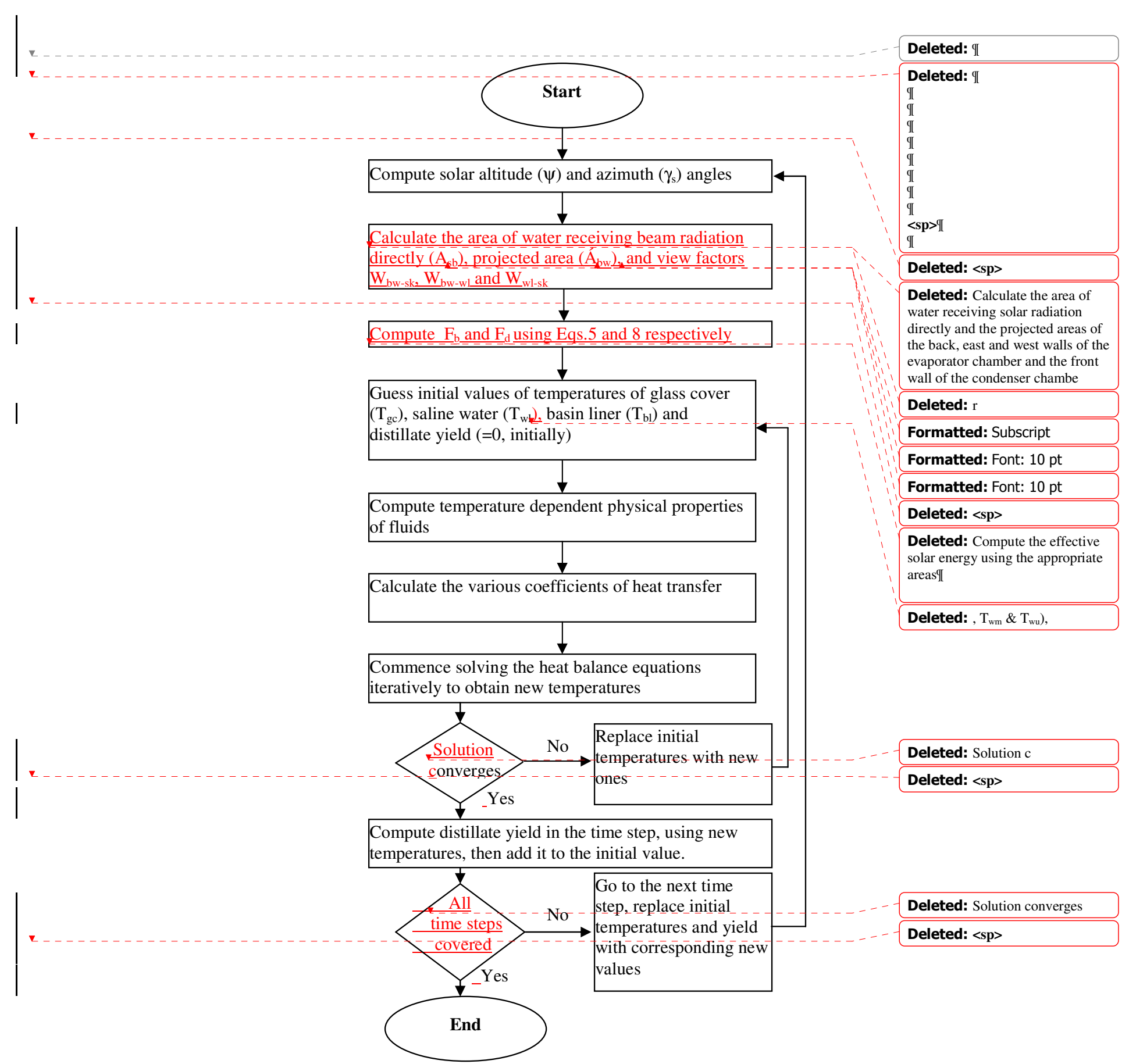

Fig.3: Flow chart for computation of the solar fractions, effective solar radiation, temperatures of system components and distillate yield in MATLAB software. 


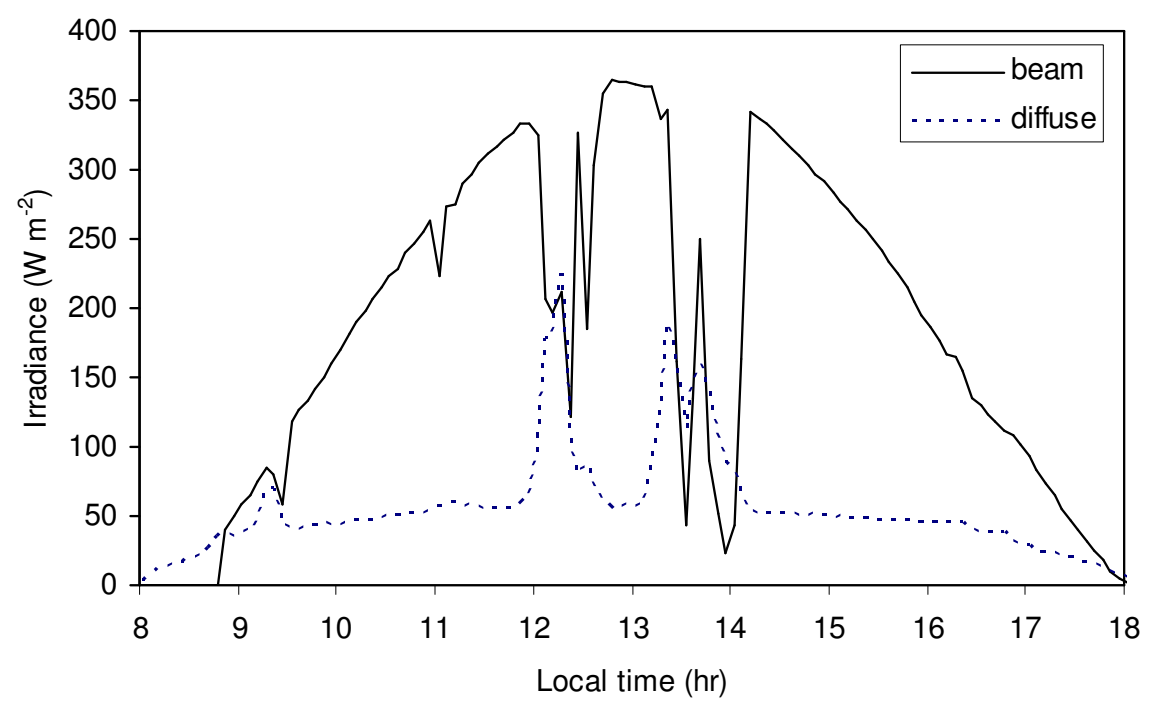

(a)

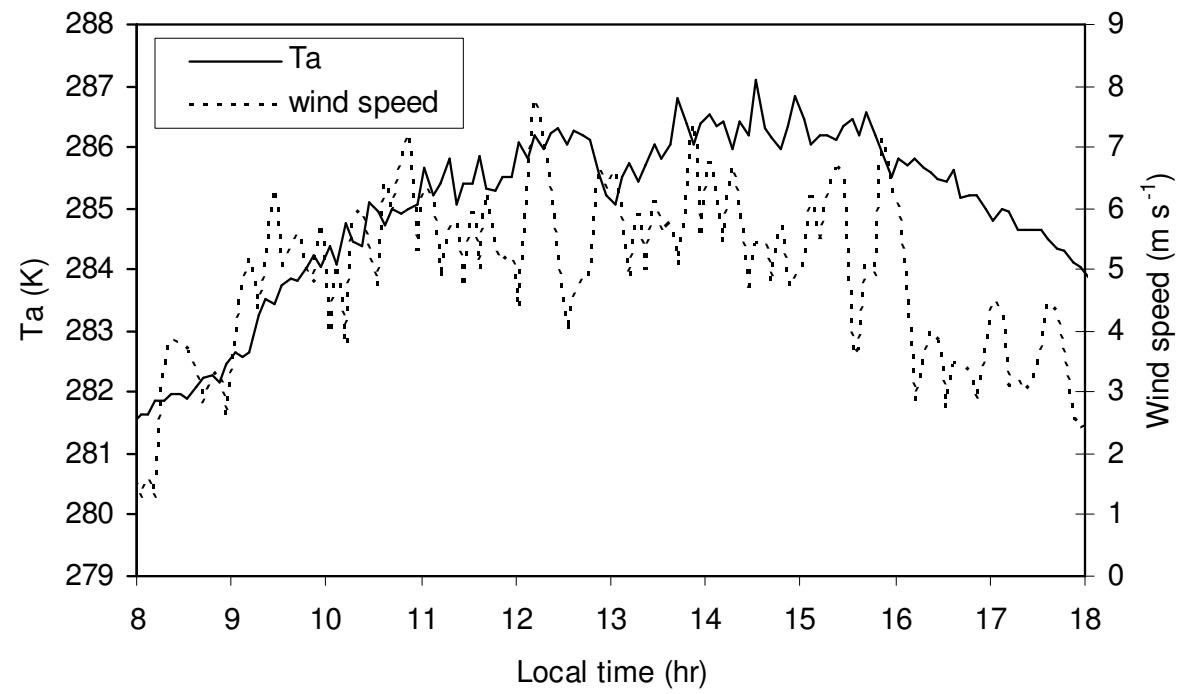

(b)

Fig.4: Variation of a) solar radiation on a horizontal surface and b) ambient air temperature and wind speed with time. 

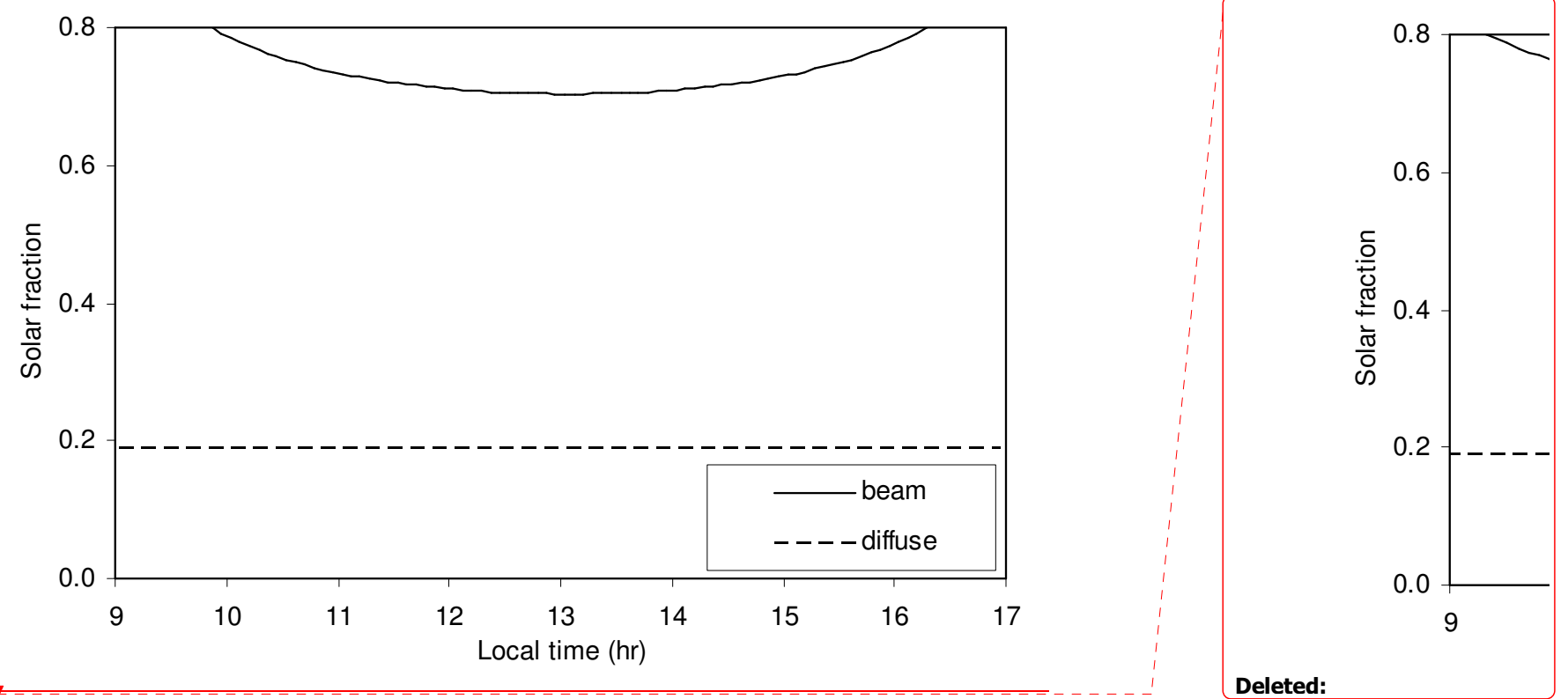

Fig.5: Variation of the beam and diffuse solar fractions with time. 


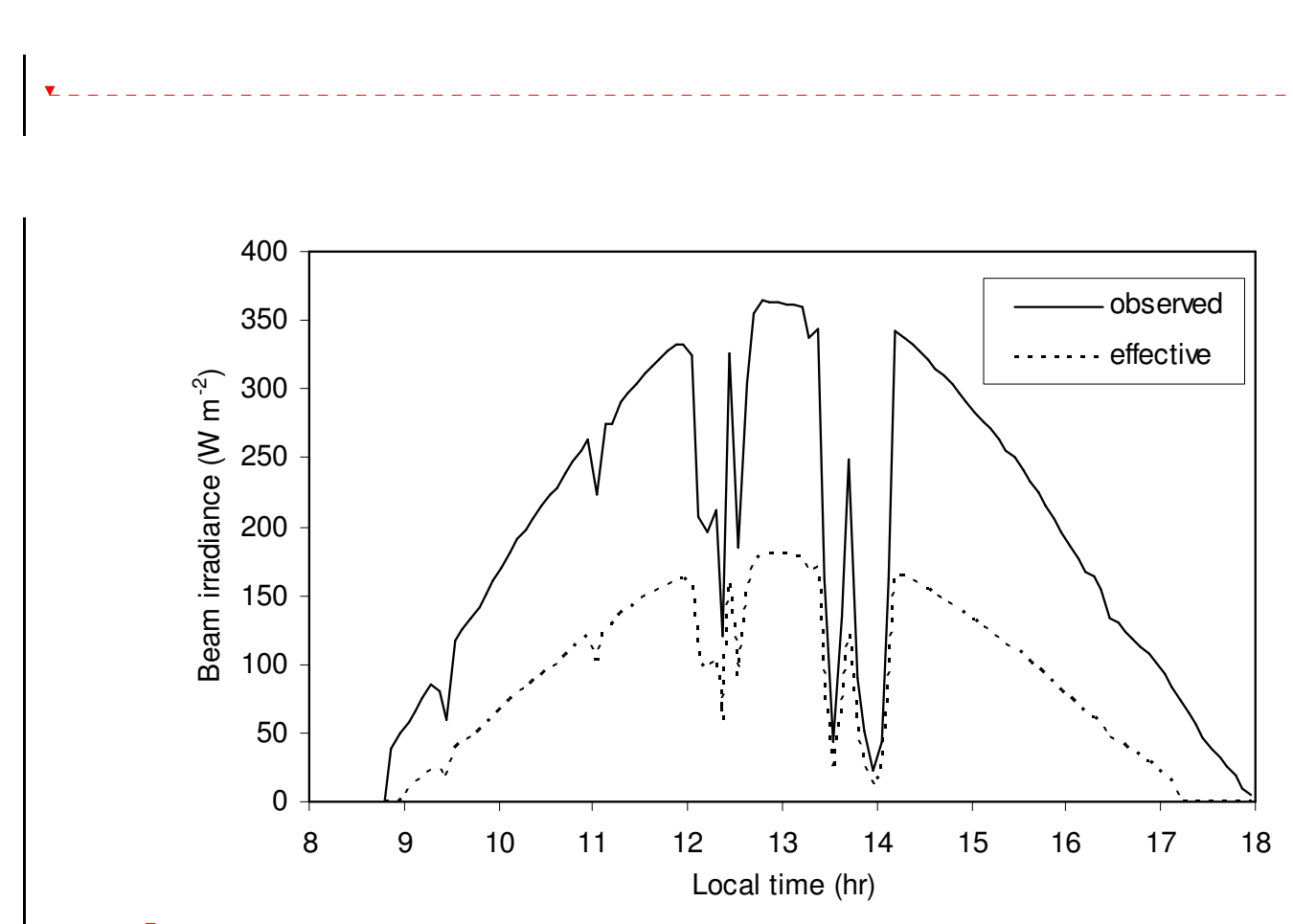

(a)

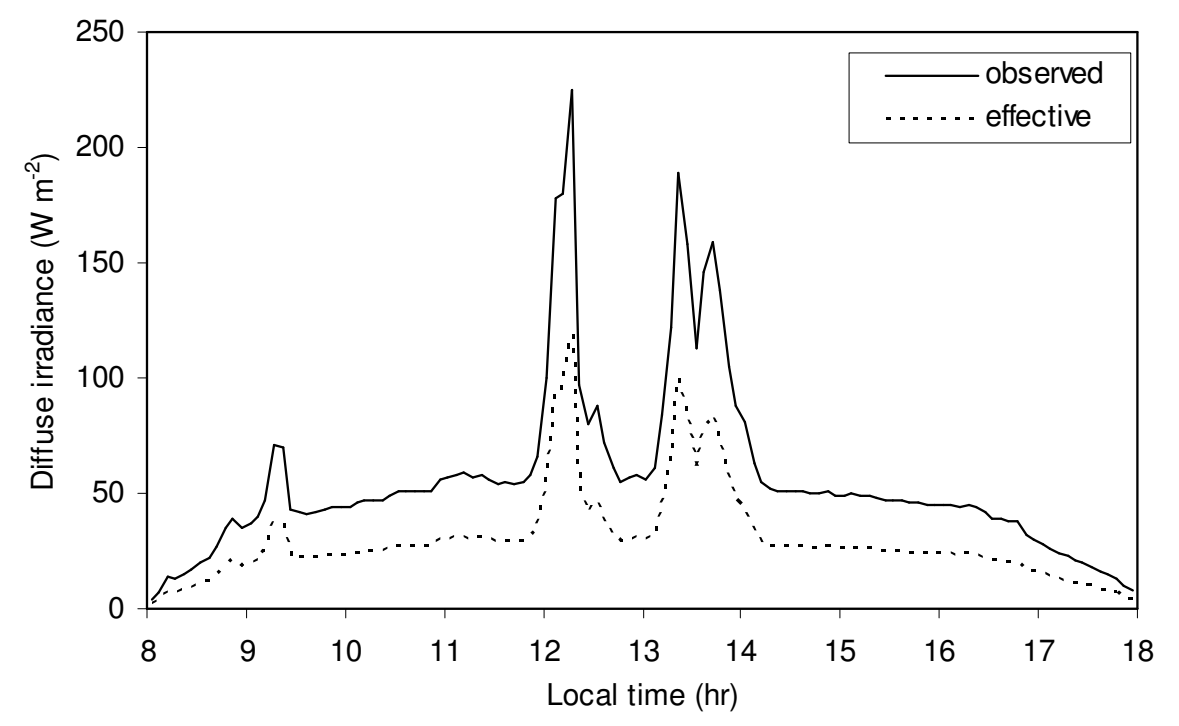

(b)
Deleted: 9

II

II

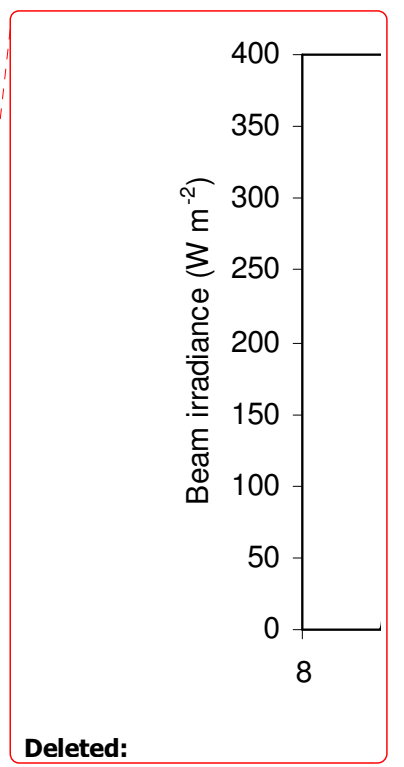

Fig.6: Variation of effective and observed a) beam b) diffuse irradiance on $17^{\text {th }}$ October 2007. 


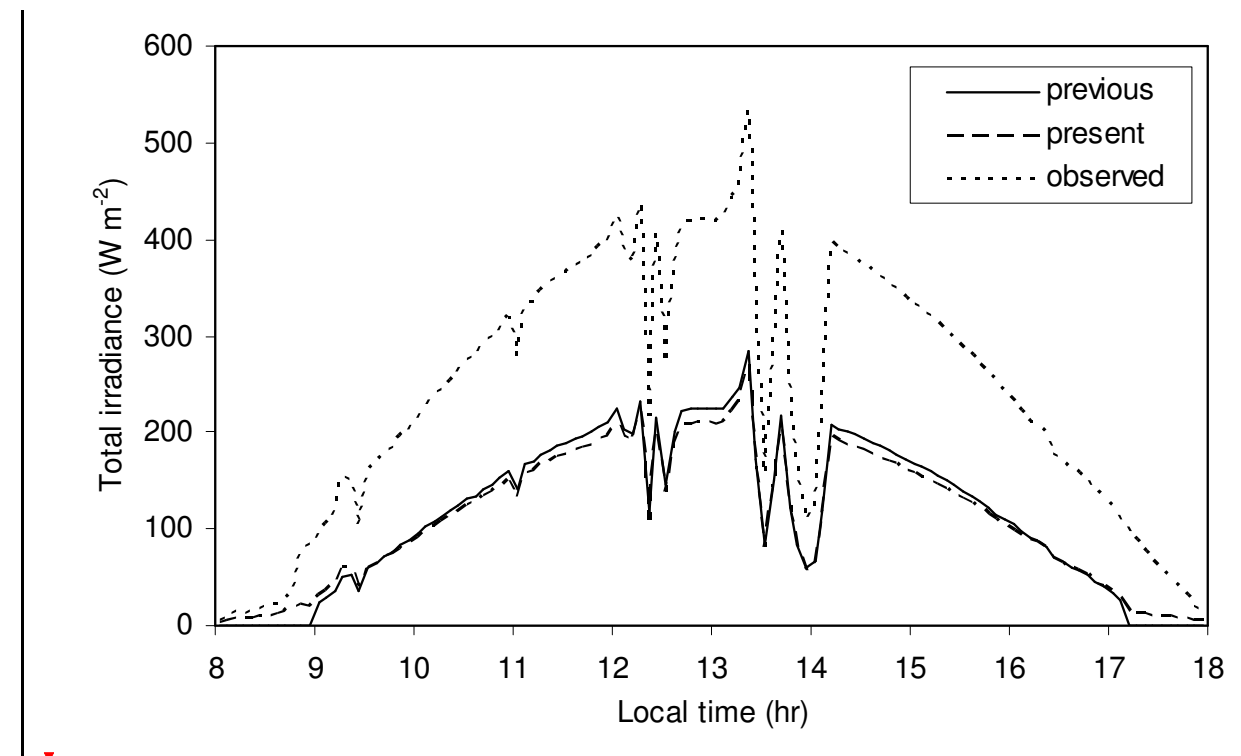

Fig. $\overline{7}$ : Variation of total effective irradiance in the solar still based on the previous and present models, and observed levels $\left(\mathrm{G}_{\mathrm{gh}}\right)$ outside the solar still

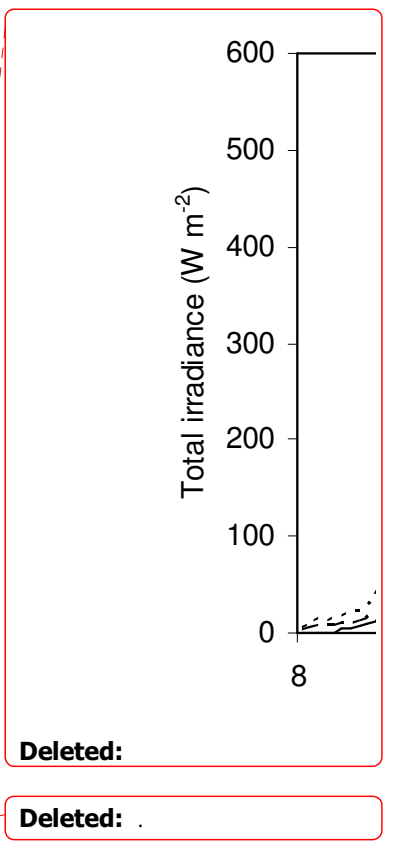

Deleted: 

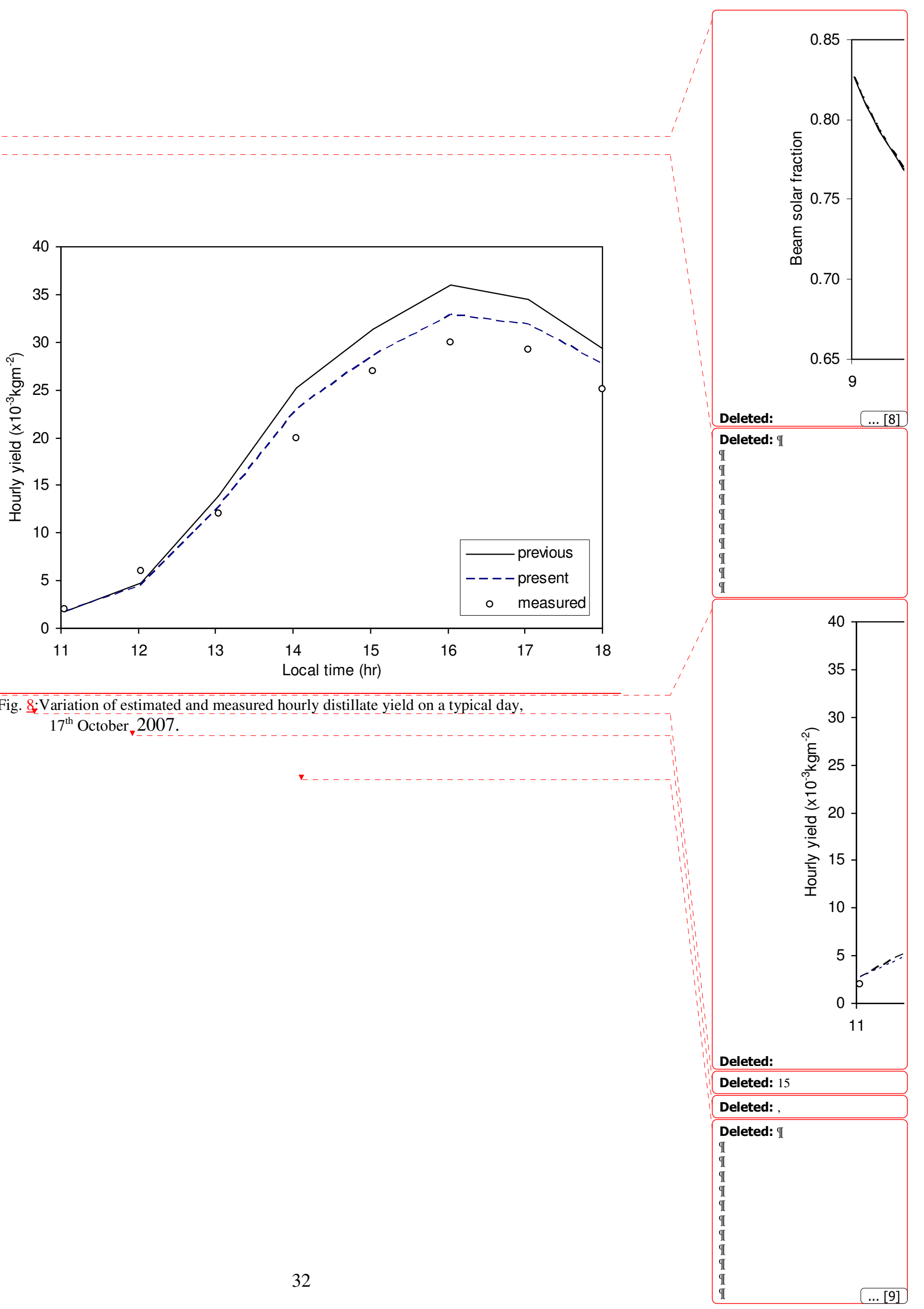


\subsection{Sensitivity analysis}

a) Optical view factors

Optical view factors influence the exchange of radiation between two given surfaces, and these factors depend on the geometries of the surfaces in question. In this section, the effect of varying the length $\left(\mathrm{L}_{\mathrm{bl}}\right)$, width $\left(\mathrm{B}_{\mathrm{bl}}\right)$ and height of the back wall $\left(\mathrm{Z}_{\mathrm{bw}}\right)$ of the solar still on the view factors that appear in equations for calculating the diffuse solar fraction (Eq.8), effective beam (Eq.10) and diffuse (Eq.12) irradiances are presented.

Table 2 shows the effects of $\mathrm{L}_{\mathrm{bl}}, \mathrm{B}_{\mathrm{bl}}$ and $\mathrm{Z}_{\mathrm{bw}}$ on the optical view factors of the back wall relative to the sky $\left(\mathrm{W}_{\mathrm{bw}-\mathrm{sk}}\right)$, back wall relative to the water surface $\left(\mathrm{W}_{\mathrm{bw}-\mathrm{wl}}\right)$ and water surface with respect to the sky $\left(\mathrm{W}_{\mathrm{wl}-\mathrm{sk}}\right)$. It is observed that all the view factors $\mathrm{W}_{\mathrm{bw}-\mathrm{sk}}$, $\mathrm{W}_{\mathrm{bw}-\mathrm{wl}}$ and $\mathrm{W}_{\mathrm{wl}-\mathrm{sk}}$ increase with the length of the still, probably due to increases in the areas of the surface of water and back wall. This shows that the proportions of diffuse solar radiation directly received by the back wall and water surface, and the fraction of beam and diffuse solar energy reflected from the back wall onto the water surface would increase with the length of the solar still.

It is also seen that that the view factors $\mathrm{W}_{\mathrm{bw}-\mathrm{wl}}$ and $\mathrm{W}_{\mathrm{wl} \text {-sk }}$ increase while $\mathrm{W}_{\mathrm{bw-sk}}$ does not significantly change with the width of the solar still. This trend is attributed to an increase in the area of water for a given area of the back wall. These results show that the amount of diffuse radiation directly received by the water surface would increase with the width 
of the still while the proportion of diffuse solar energy intercepted by the wall is not affected by $\mathrm{B}_{\mathrm{bl}}$. In addition, the proportion of the beam and diffuse solar energy reflected from the back wall onto the water surface is augmented by an increase in $B_{b l}$.

It is observed that all the view factors $\mathrm{W}_{\mathrm{bw}-\mathrm{sk}}, \mathrm{W}_{\mathrm{bw}-\mathrm{wl}}$ and $\mathrm{W}_{\mathrm{wl}-\mathrm{sk}}$ decrease with increasing the height of the back wall $\left(\mathrm{Z}_{\mathrm{bw}}\right)$, with a marginal effect on $\mathrm{W}_{\mathrm{bw}-\mathrm{sk}}$. This trend is ascribed to an increase in the area of the back wall for a given area of the water surface. It should also be mentioned that the back wall is obstructed (from viewing the sky) by the front, east and west walls. In particular, the areas of the east and west walls also increase with the height of the back wall, which reduces the proportion of the sky viewed by the wall. Without obstruction, the back wall would view a higher percentage of the sky as $\mathrm{Z}_{\mathrm{bw}}$ increases. These results show that the amount of diffuse radiation directly received by the water surface and back wall would decrease as the height of the solar still increases. In addition, the proportion of the beam and diffuse solar energy reflected from the back wall onto the water surface would decrease with increasing the height of the wall.

\section{b) Solar fraction}

The effect of varying the length $\left(\mathrm{L}_{\mathrm{bl}}\right)$, width $\left(\mathrm{B}_{\mathrm{bl}}\right)$ and height $\left(\mathrm{Z}_{\mathrm{bw}}\right)$ of the solar still on solar fraction and effective solar irradiance on a typical day is presented in this section. Fig.8 shows the effect $\mathrm{L}_{\mathrm{bl}}$ on solar fraction. It is observed that $\mathrm{L}_{\mathrm{bl}}$ has no effect on the beam solar fraction as expected from Eq.(5). This observation conforms to previous results (Tripathi and Tiwari, 2004). In contrast, the diffuse solar fraction increases with 
$\mathrm{L}_{\mathrm{bl}}$ probably due to increases in the proportions of the sky viewed by the water surface and back wall (Table 2).

Fig.9 shows the effect of width $\left(B_{b 1}\right)$ on solar fraction. It is observed that both the beam and diffuse solar fractions decrease with increasing $\mathrm{B}_{\mathrm{b}}$, probably due to an increase in the area of water that receives solar radiation directly for a given area of the back wall. The observed effect of $\mathrm{B}_{\mathrm{bl}}$ on solar fraction is again consistent with previous findings (Tripathi and Tiwari, 2004).

The effect of the height of the back wall $\left(Z_{\mathrm{bw}}\right)$ on the beam and diffuse solar fractions is shown in Fig.10. It is seen that both solar fractions increase with $\mathrm{Z}_{\mathrm{bw}}$. This observation is attributed to an increase in the area of the wall (and its projected area) which augments solar radiation intercepted by the wall for a given basin area. Tripathi and Tiwari (2004) also observed that the solar fraction on the back wall increased with the height of the wall.

c) Effective irradiance

Fig.11 shows the effect of $\mathrm{L}_{b l}$ on the effective irradiance. It is observed that the effective beam irradiance is insensitive to $\mathrm{L}_{\mathrm{bl}}$. From Eq.(10), the view factor of the back wall with respect to the water surface $\left(\mathrm{W}_{\mathrm{wb}-\mathrm{wl}}\right)$ increases by a small margin while the other parameters remain constant, which results in an insignificant influence on the effective beam irradiance when the length of the solar still is increased. It is seen that the effective diffuse irradiance $\left(\mathrm{G}_{\mathrm{de}}\right)$ increases with the length of the still. This trend is attributed to increases in the view factors and the diffuse solar fraction in Eq.(12). Tripathi and Tiwari 
(2004) observed that the length of the distiller did not influence the effective solar irradiance inside a single-slope solar still, in conformity with the present findings for beam radiation only.

The effect of the width of the solar still $\left(\mathrm{B}_{\mathrm{bl}}\right)$ on the effective beam and diffuse solar irradiances is shown in Fig.12. It is observed that both the effective beam and diffuse irradiances increase with $\mathrm{B}_{\mathrm{bl}}$, probably due to an increase in the solar radiation intercepted by the base area of the still. Tripathi and Tiwari (2004) also report that the amount of solar radiation falling on the base of the still increases with $B_{b l}$ but they found that the effective irradiance decreased with the width of the still. The discrepancy between the previous and present findings may be due to differences in the computational techniques employed.

Fig.13 shows the effect of the height of the back wall of the solar still $\left(\mathrm{Z}_{\mathrm{bw}}\right)$ on the effective beam and diffuse solar irradiances. It is observed that the effective solar irradiance marginally increases with $\mathrm{Z}_{\mathrm{bw}}$, probably due to an increase in the total area of the wall (and its corresponding projection). It is nevertheless seen that the effective diffuse irradiance decreases with increasing the height of the back wall which is probably due to decreases in the view factors $\mathrm{W}_{\mathrm{bw}-\mathrm{sk}}$ and $\mathrm{W}_{\mathrm{bw}-\mathrm{sk}}$ (Table 2). Tripathi and Tiwari (2004) found that the effective irradiance inside a solar still increased with $\mathrm{Z}_{\mathrm{bw}}$, in agreement with the present results for beam radiation only. $\left(\mathrm{T}_{\mathrm{gc}}\right)$ and water in the basin $\left(\mathrm{T}_{\mathrm{wl}}\right)$ with time on a typical day. For the glass temperature, it 
is observed that $\mathrm{T}_{\mathrm{gc}}$ is intermittent probably due to the relatively low thermal mass of the glass. The previous model gives slightly higher values of $\mathrm{T}_{\mathrm{gc}}$ than those of the present model, commensurate with the computed effective irradiances. Both models slightly underestimate the values of $\mathrm{T}_{\mathrm{gc}}$ in the morning with better conformity in the afternoon. For the temperature of saline water, it is observed that the experimental $\mathrm{T}_{\mathrm{wl}}$ changes smoothly because of the relatively high thermal mass of the water. Again, the previous model gives higher values of $\mathrm{T}_{\mathrm{wl}}$ than those of the present model. It is observed that the two models slightly underestimate $\mathrm{T}_{\mathrm{wl}}$. However, there is satisfactory agreement between measured and estimated data. The estimated temperatures were used to predict the distillate yield from the solar still.

Fig.16 shows the variation of the daily distillate yield on 22 test days. It is seen that there is reasonable agreement between estimated and measured data for both the previous and present models. However, the former model produces higher estimates of the daily yield than the latter on most of the days. These observations are again commensurate with the computed effective irradiances. In addition, $r$ 
Table 2: Variation of view factors used in computing $F_{d}, G_{b e}$ and $G_{d e}$, as the design parameters are increased from the lower to the upper studied limits.

\begin{tabular}{llll}
\hline \multirow{2}{*}{$\begin{array}{l}\text { Design } \\
\text { parameter }\end{array}$} & \multicolumn{3}{l}{ Range of view factor obtained } \\
\cline { 2 - 4 } & $\mathrm{W}_{\mathrm{bw}-\mathrm{sk}}$ & $\mathrm{W}_{\mathrm{bw}-\mathrm{wl}}$ & $\mathrm{W}_{\mathrm{wl}-\mathrm{sk}}$ \\
\hline $\mathrm{L}_{\mathrm{bl}}$ & $0.17-0.25$ & $0.26-0.30$ & $0.46-0.54$ \\
$\mathrm{~B}_{\mathrm{bl}}$ & $0.23-0.23$ & $0.27-0.30$ & $0.48-0.56$ \\
$\mathrm{Z}_{\mathrm{bw}}$ & $0.23-0.22$ & $0.30-0.21$ & $0.54-0.40$ \\
\hline
\end{tabular}




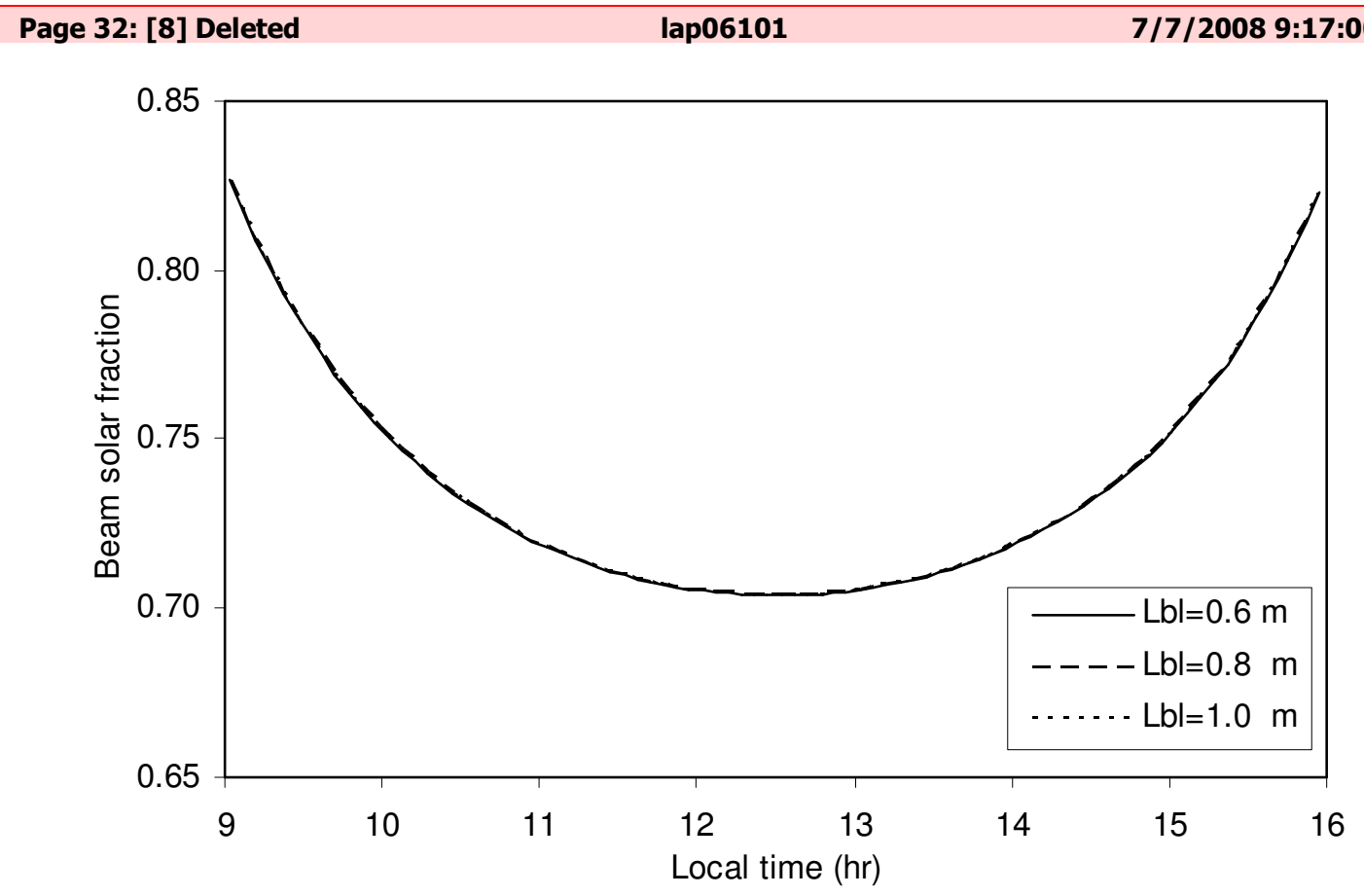

(a) 


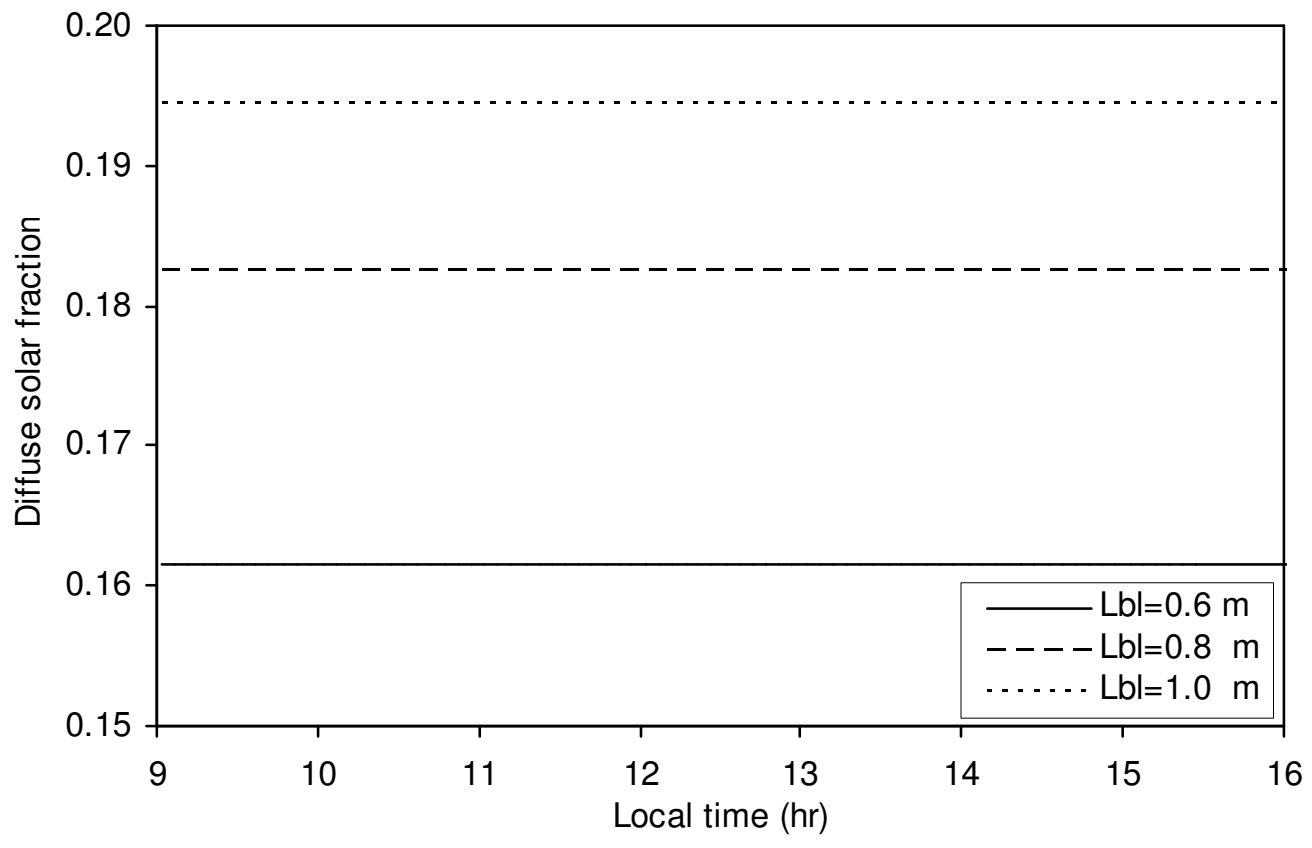

Fig.8: Effect of the length of the solar still on a) beam and b) diffuse solar fractions. 


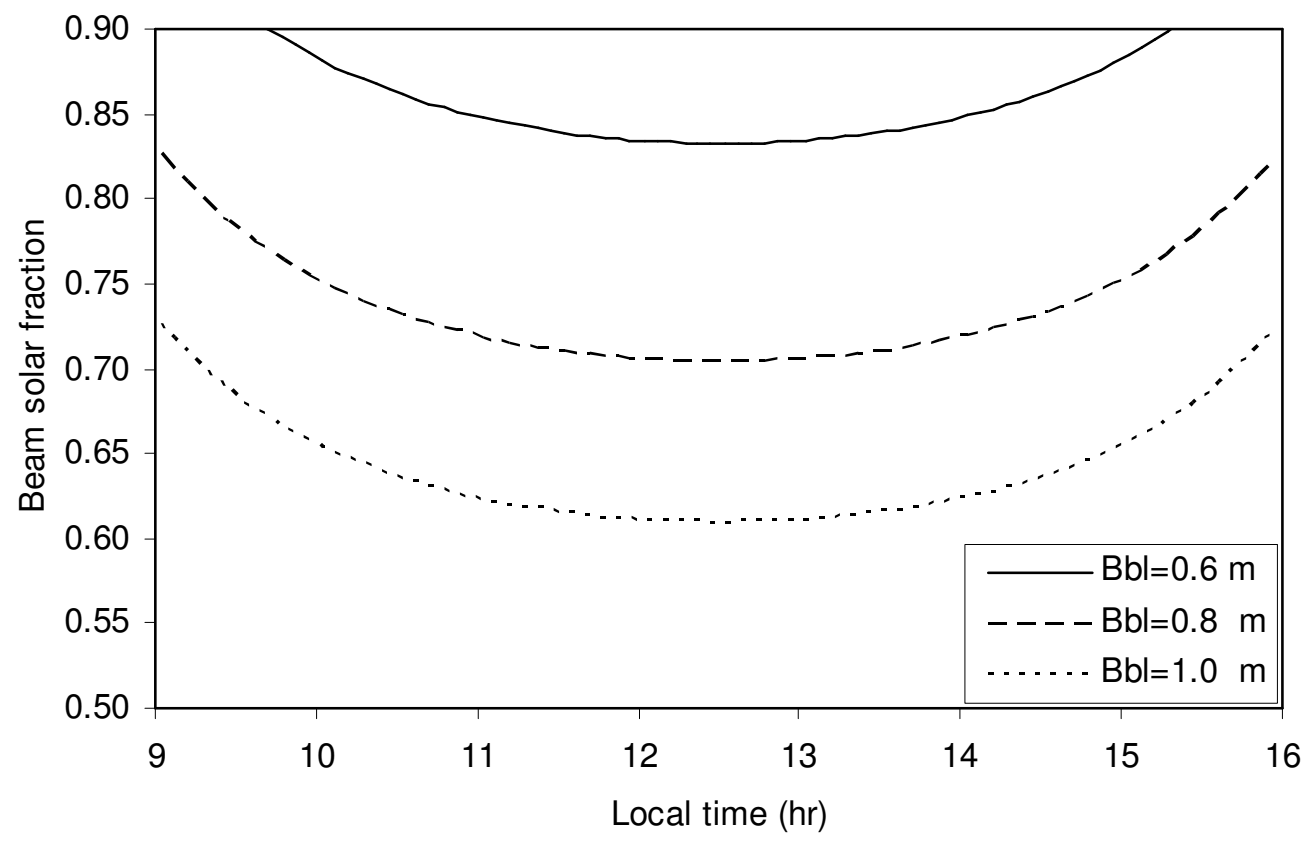

(a)

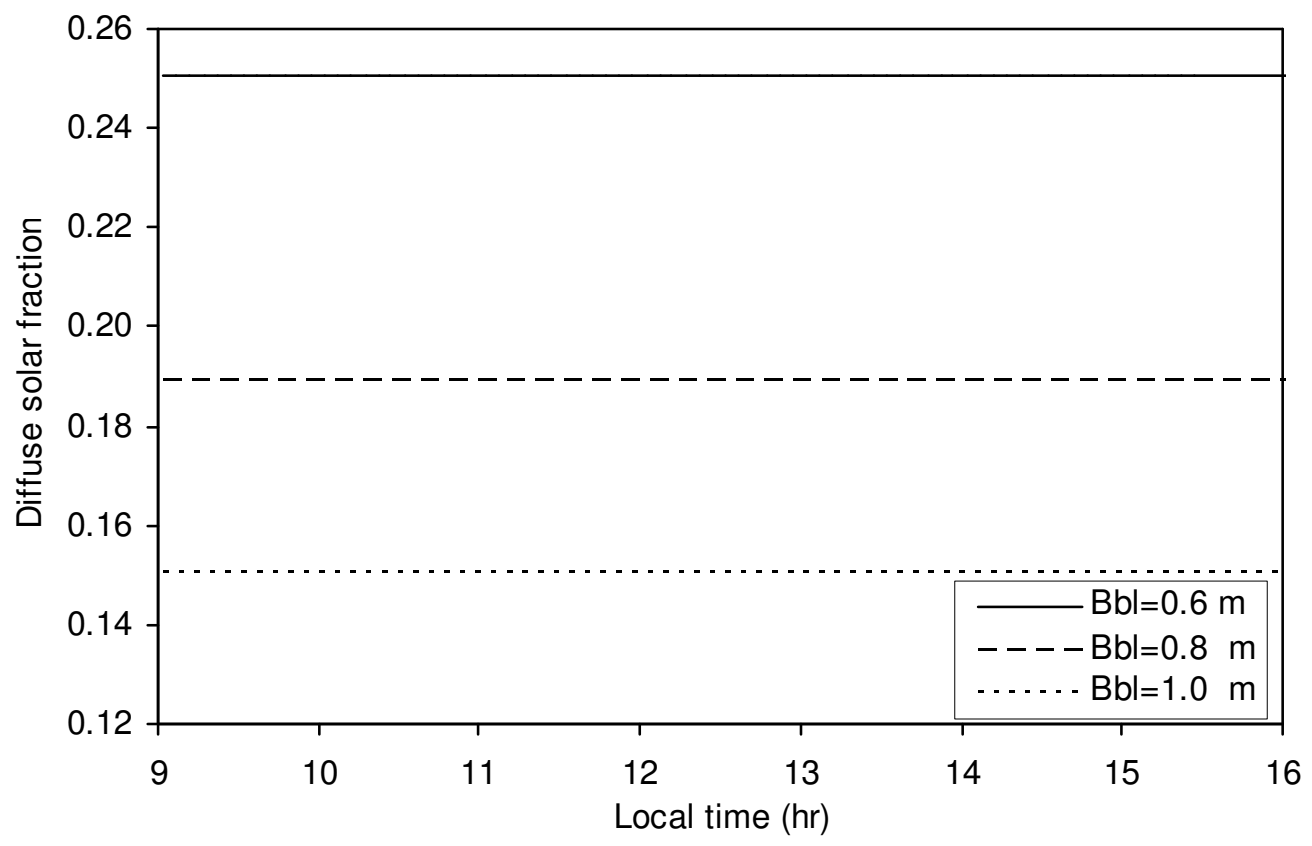

(b)

Fig.9: Effect of width of solar still $\left(\mathrm{B}_{\mathrm{bl}}\right)$ on a) beam and b) diffuse solar fractions. 


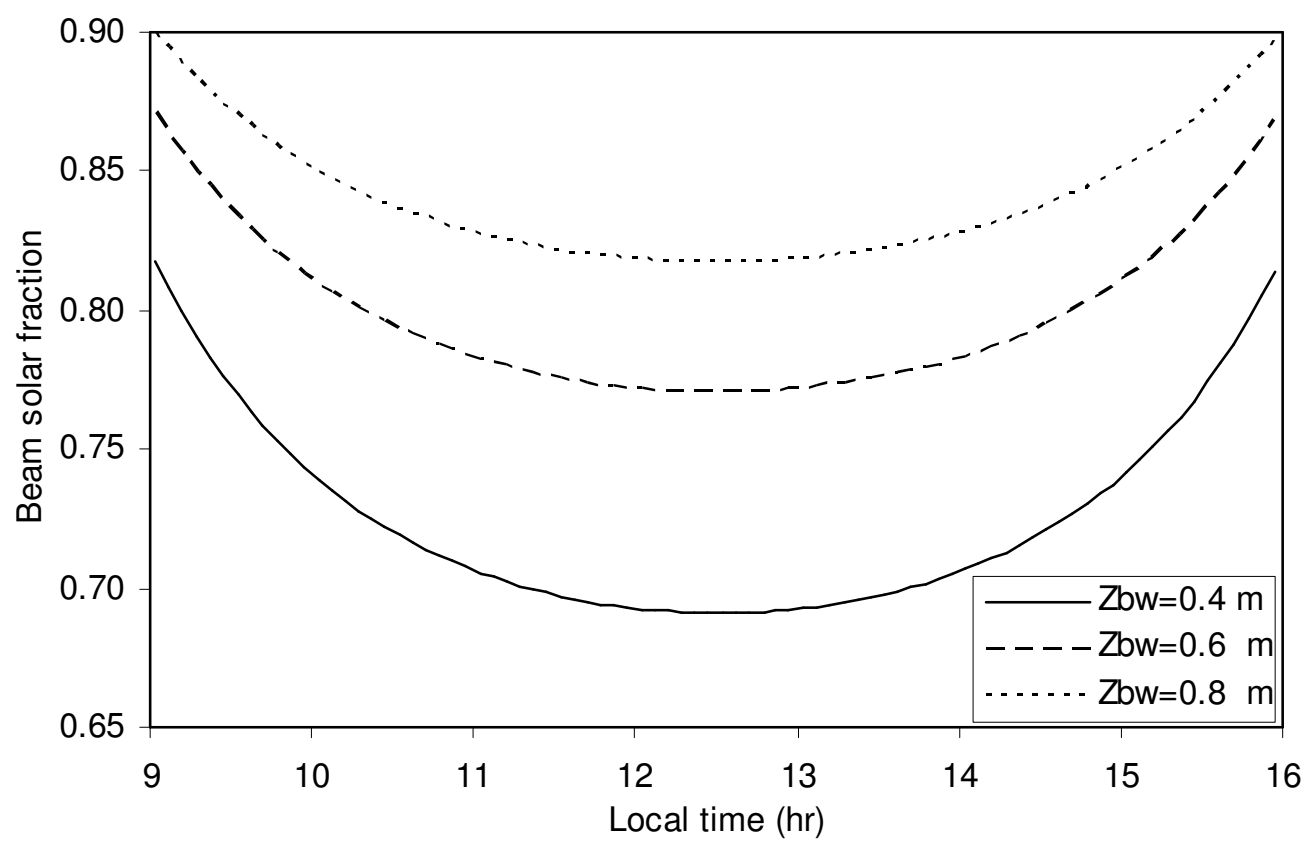

(a)

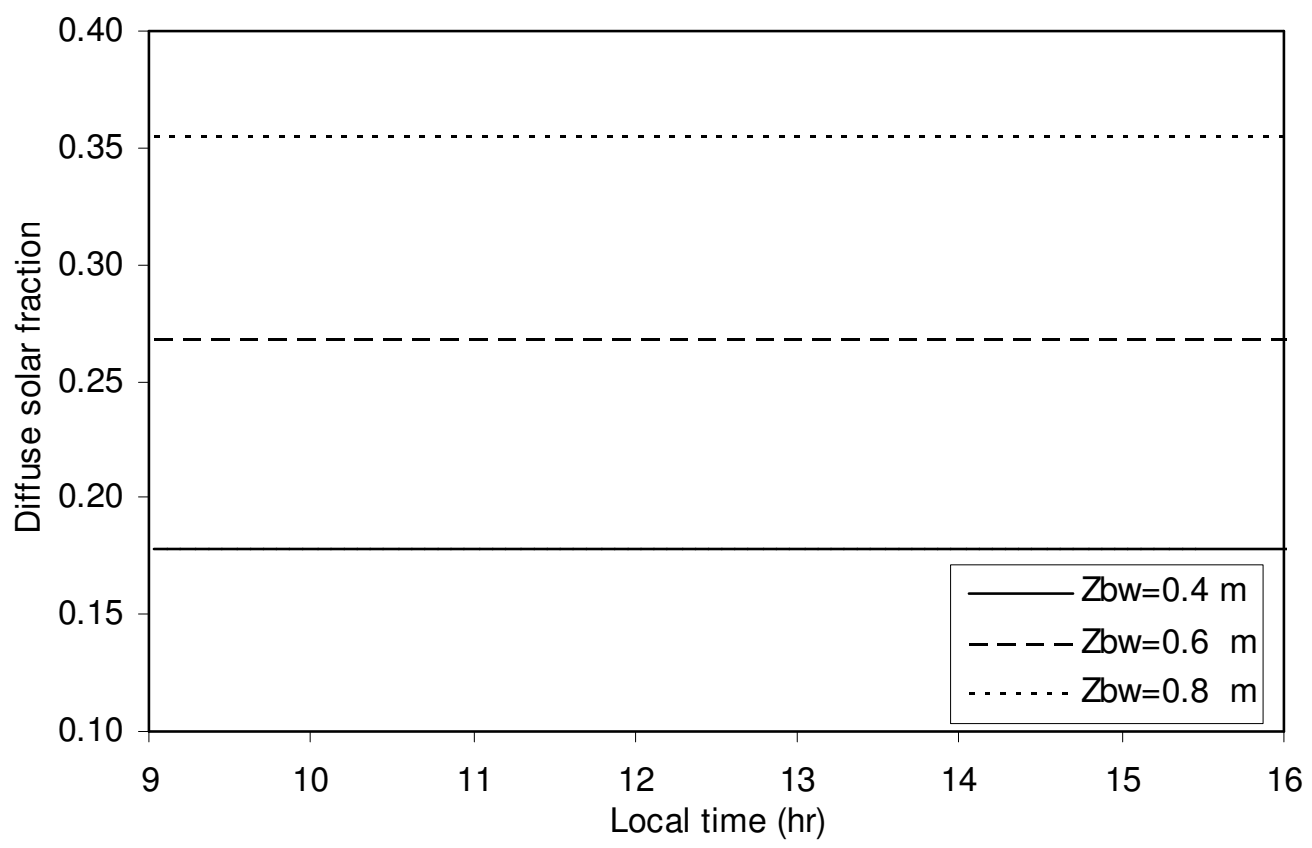

(b)

Fig.10: Effect of height of back wall ( $\left.Z_{b w}\right)$ of solar still on a) beam and $b$ ) diffuse solar fraction. 


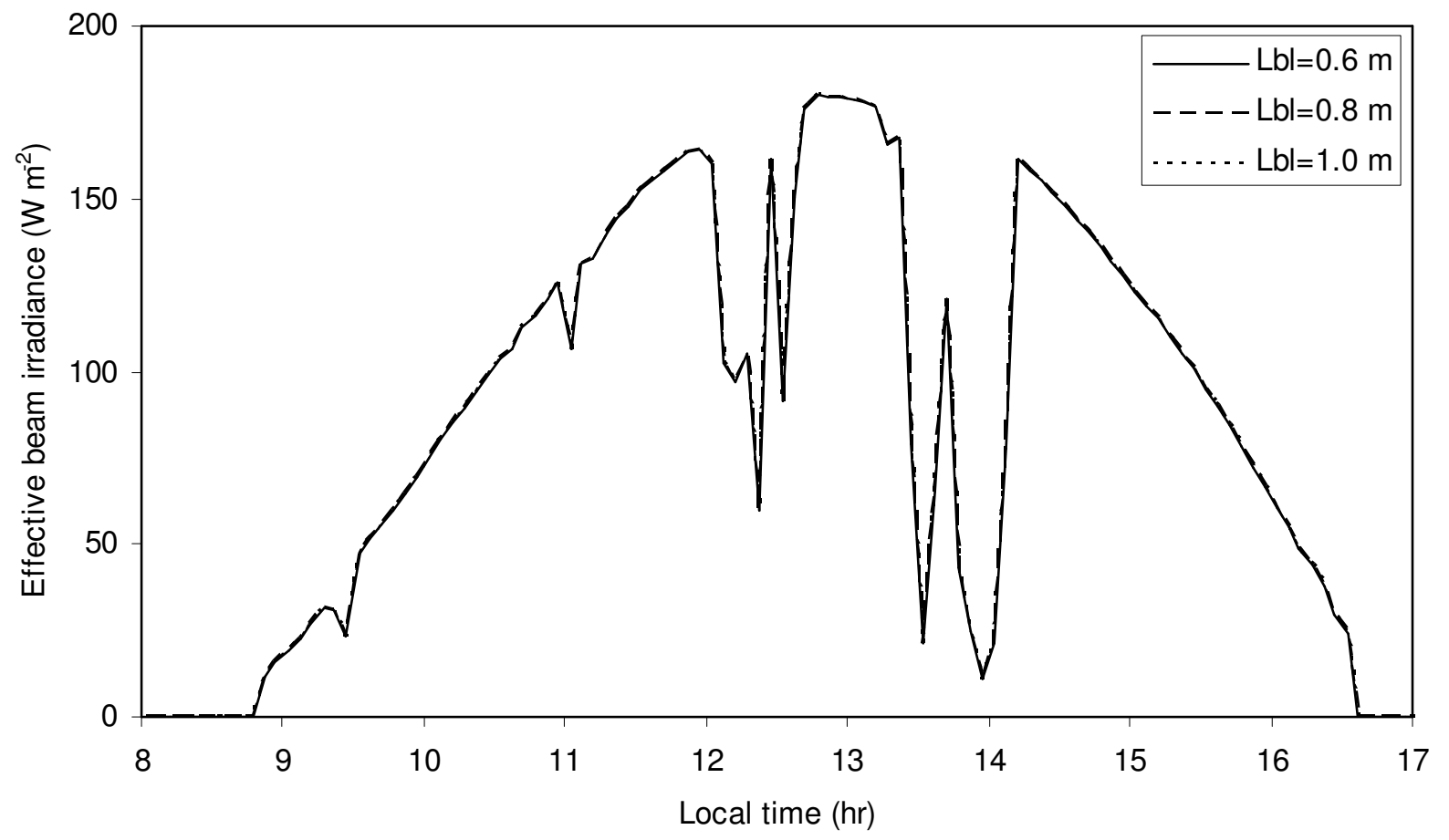

(a) 


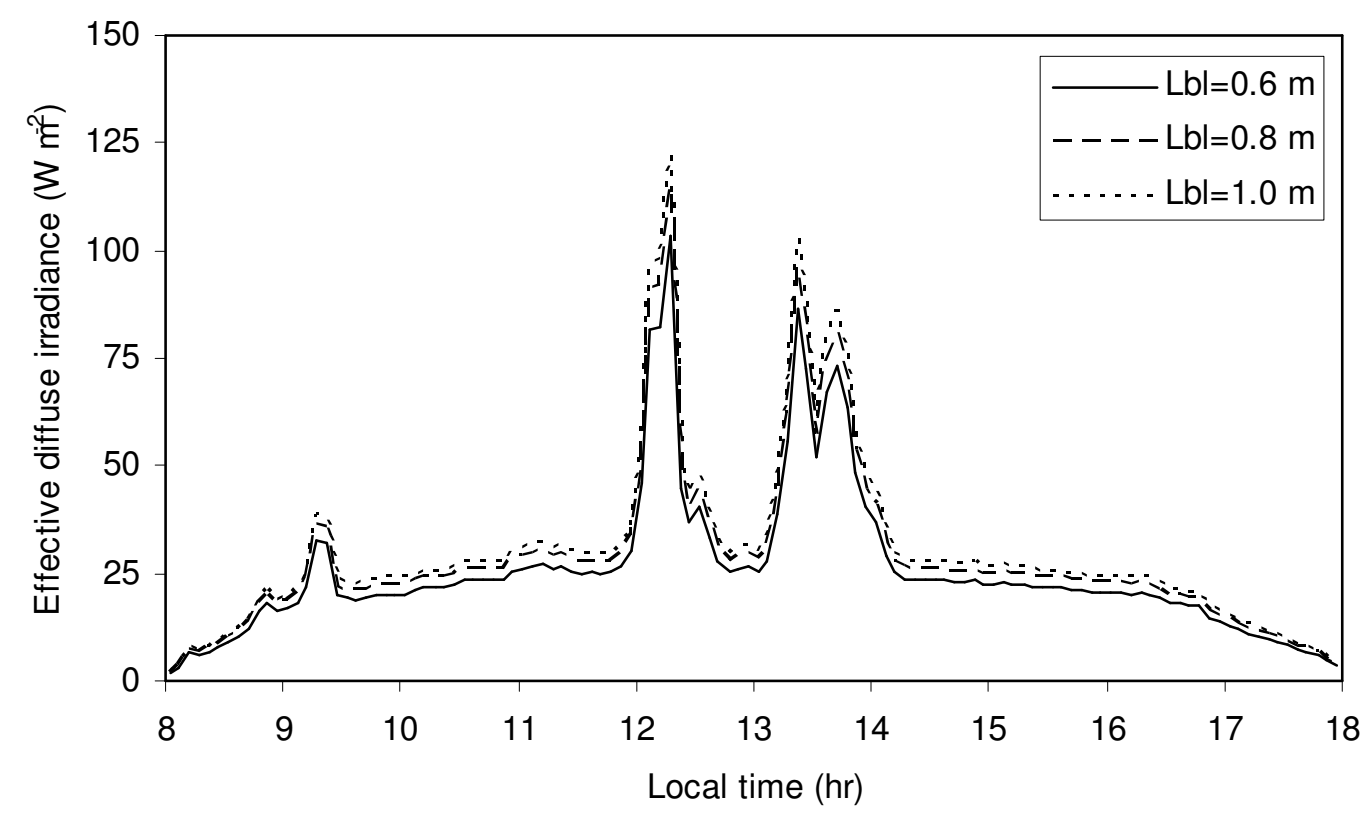

(b)

Fig.11: Effect of the length $\left(\mathrm{L}_{b 1}\right)$ of the solar still on the effective a) beam and b) diffuse irradiances.

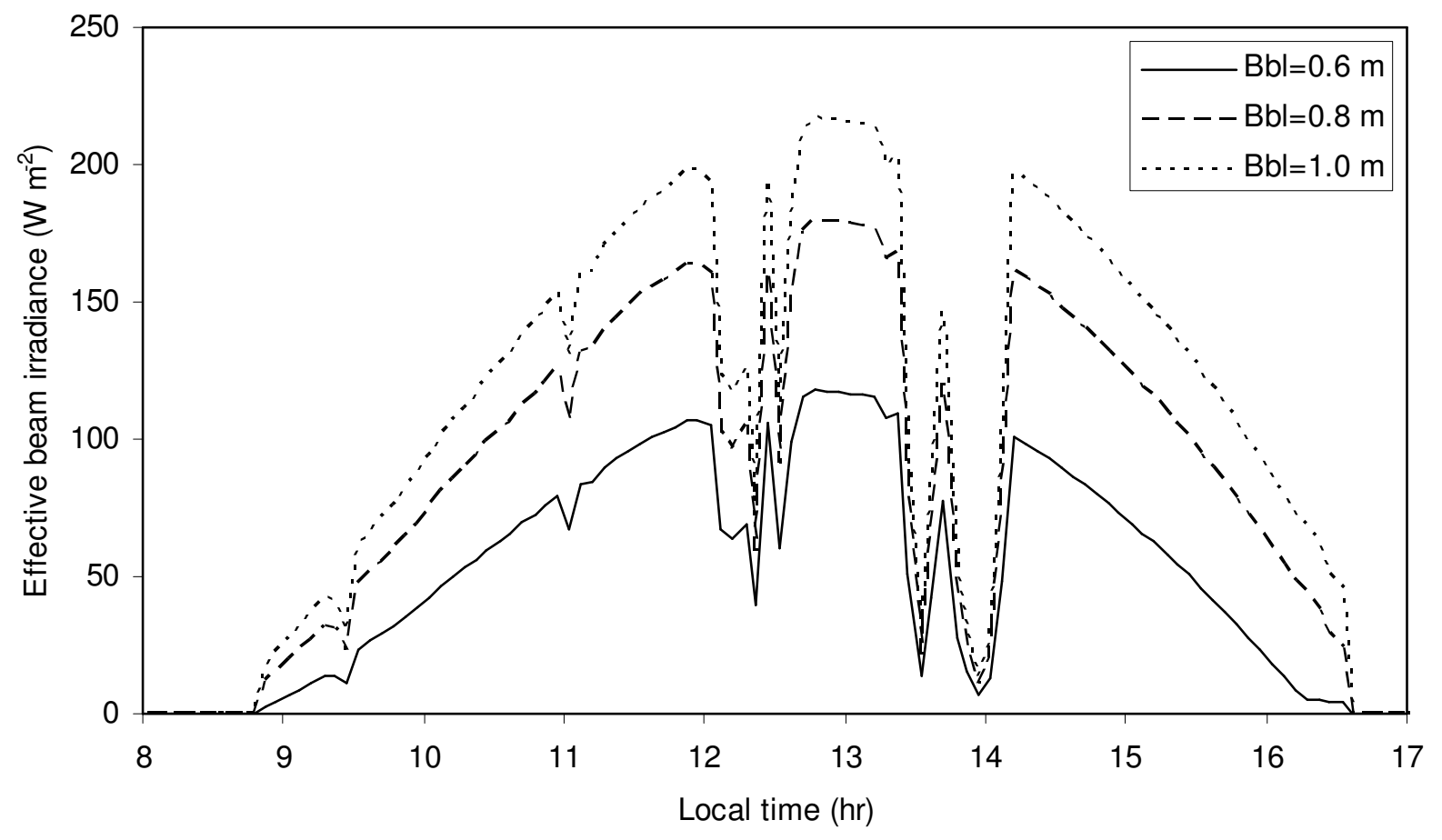

(a) 


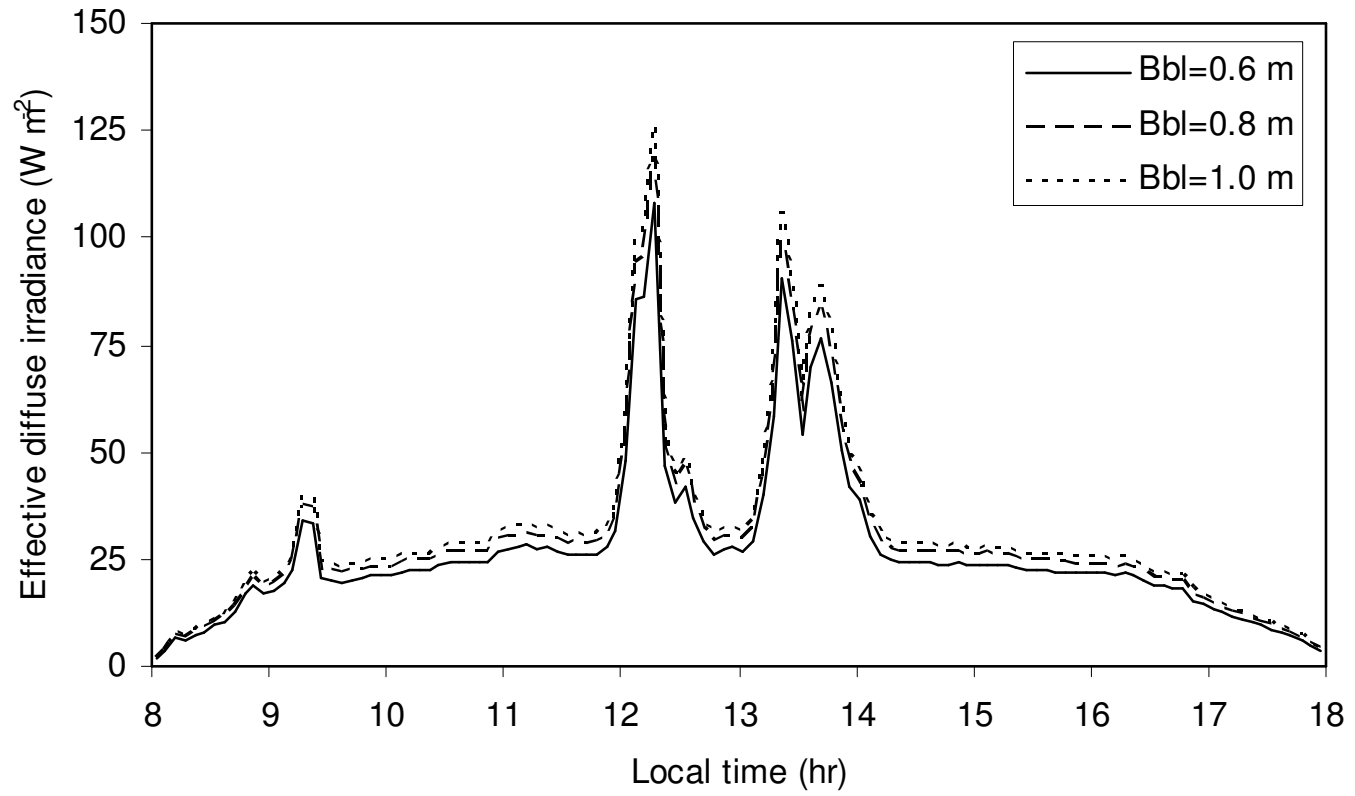

(b)

Fig.12: Effect of the width $\left(B_{b 1}\right)$ of the solar still on the effective a) beam and $\left.b\right)$ diffuse irradiances.

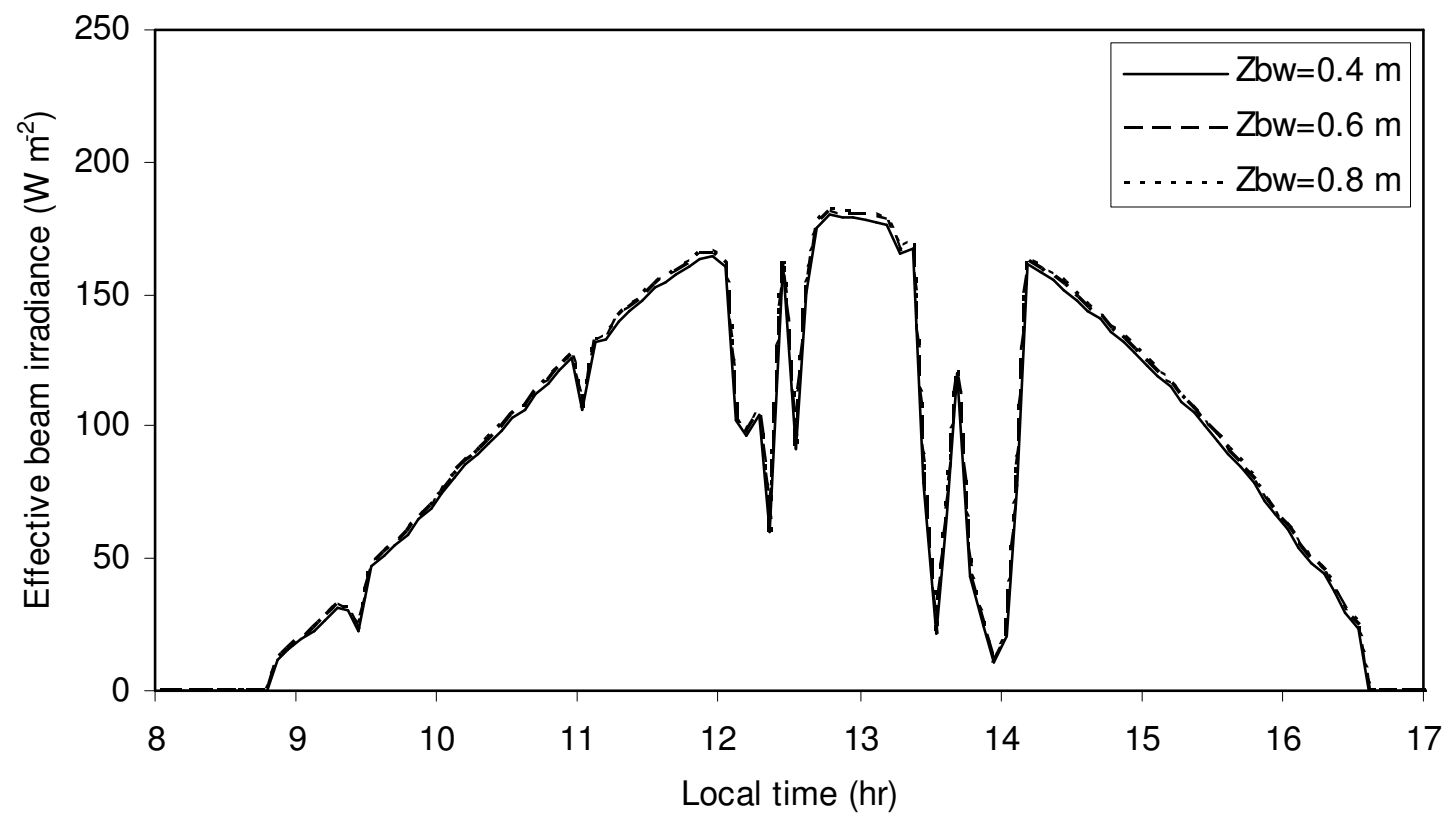

(a) 


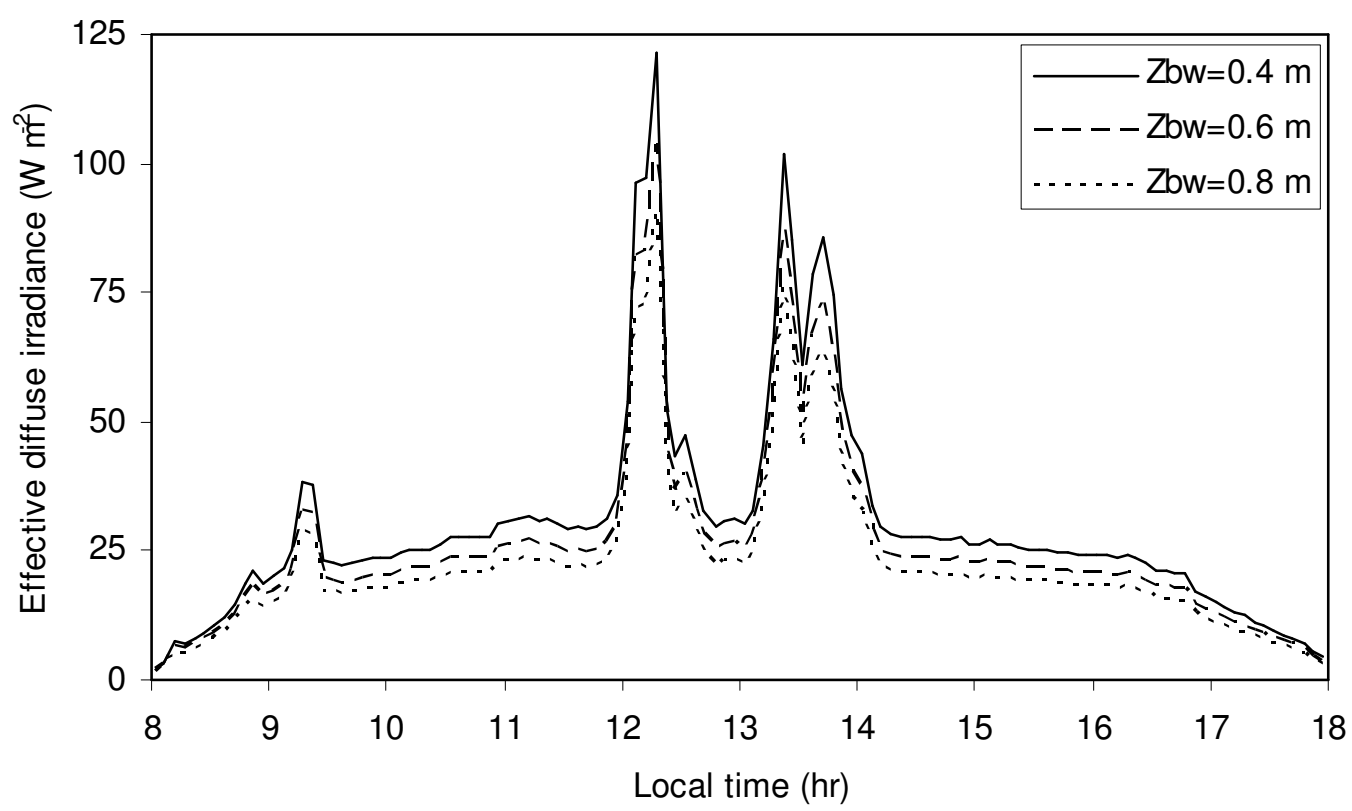

(b)

Fig.13: Effect of height of back wall $\left(Z_{n w}\right)$ of solar still on effective a) beam and $\left.b\right)$ diffuse irradiance.

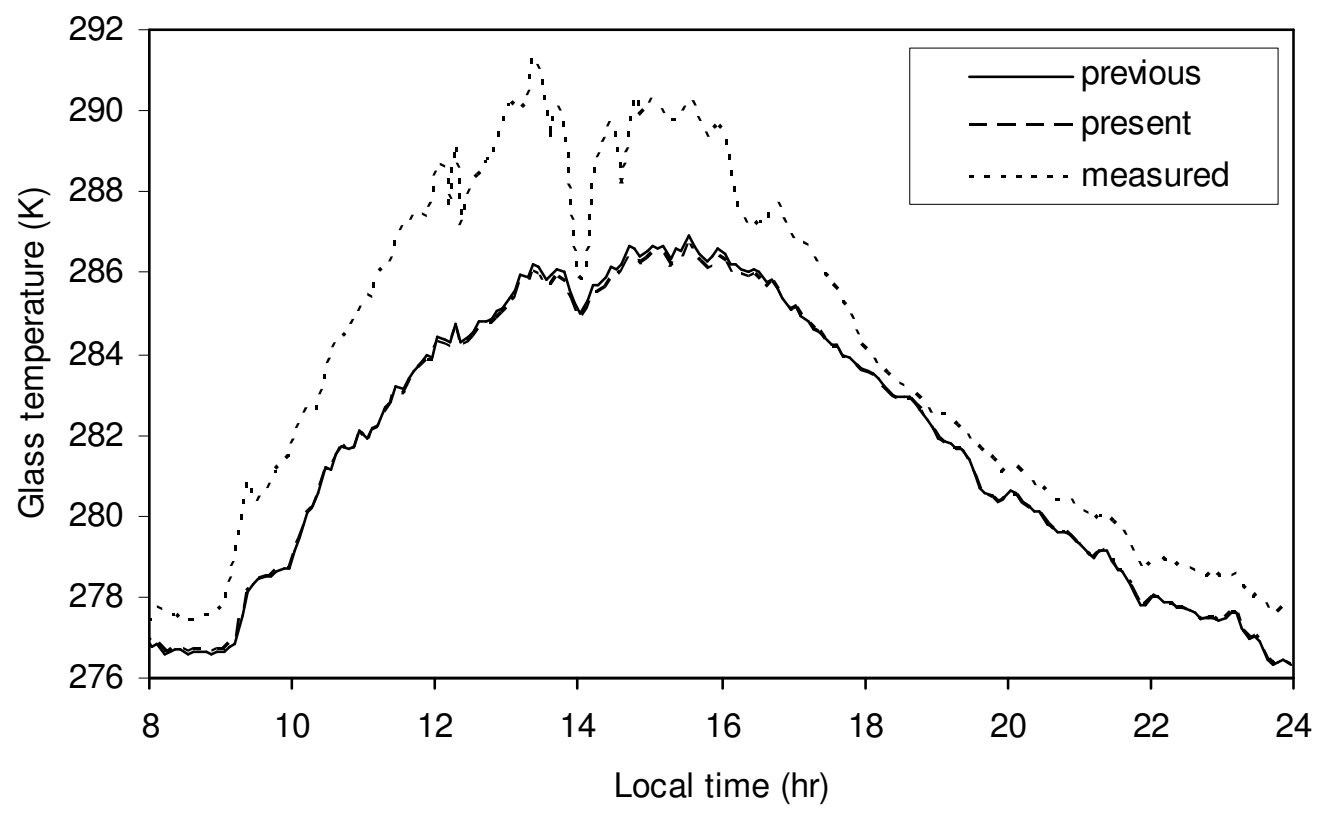

(a) 


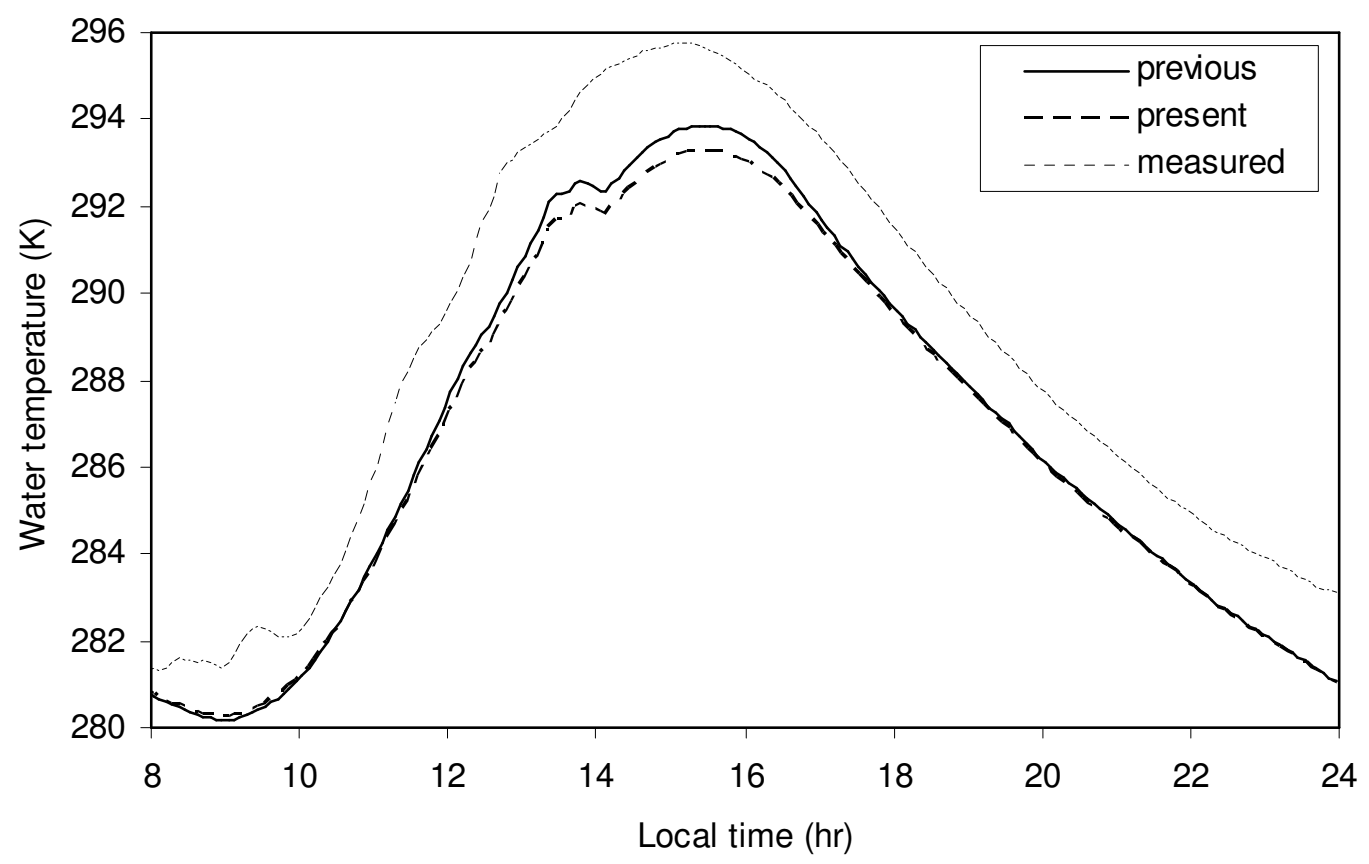

(b)

Fig.14: Variation of a) glass and b) water temperatures for estimated and measured with time. 


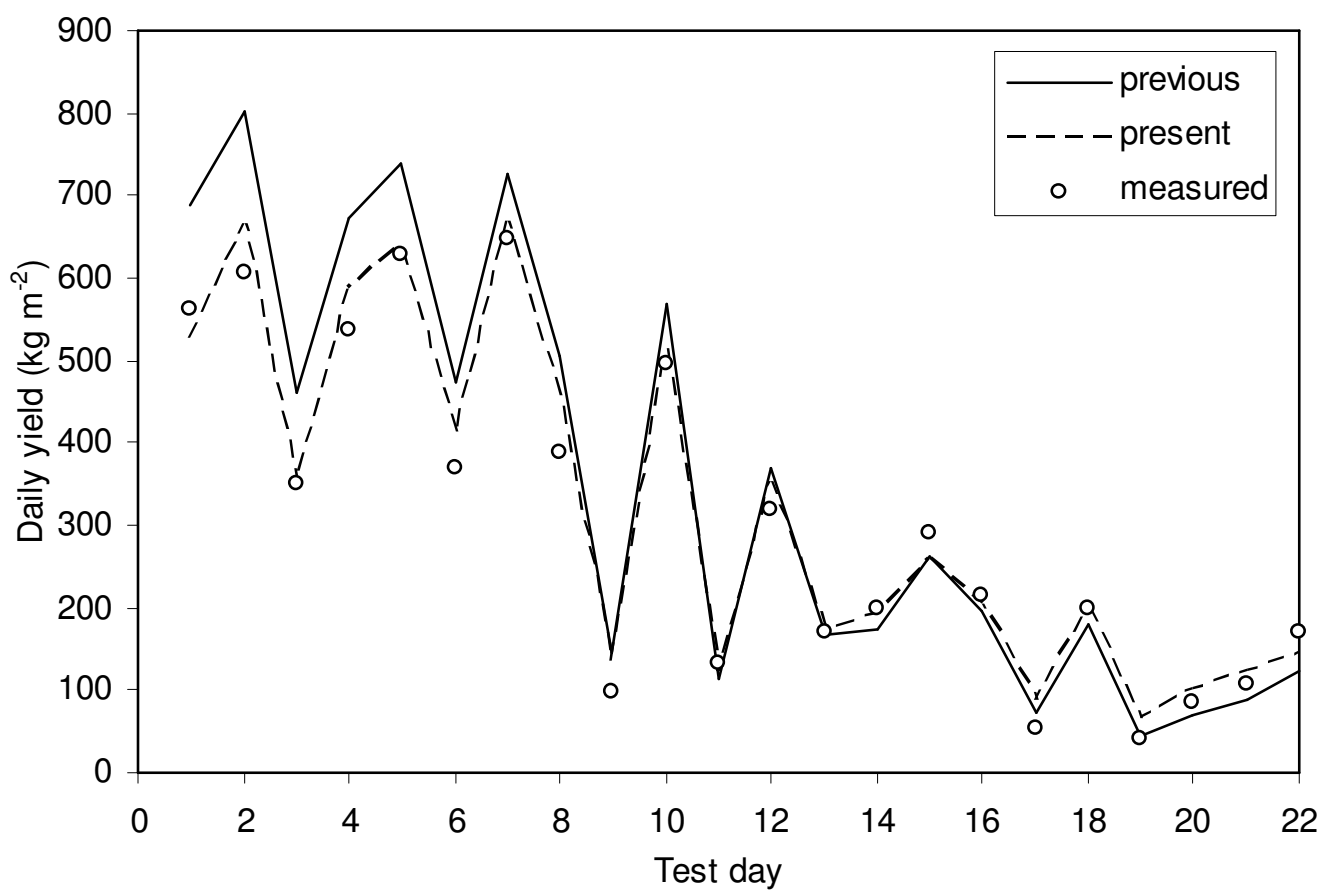

Fig.16: Variation of estimated and measured daily distillate yield. 